\title{
The effect of horizontal resolution on the representation of the global monsoon annual cycle in Atmospheric General Circulation Models
}

Article

Accepted Version

Zhang, L., Zhou, T., Klingaman, N. P., Wu, P. and Roberts, M. (2018) The effect of horizontal resolution on the representation of the global monsoon annual cycle in Atmospheric General Circulation Models. Advances in Atmospheric Sciences, 35 (8). pp. 1003-1020. ISSN 0256-1530 doi:

https://doi.org/10.1007/s00376-018-7273-9 Available at https://centaur.reading.ac.uk/75426/

It is advisable to refer to the publisher's version if you intend to cite from the work. See Guidance on citing.

To link to this article DOI: http://dx.doi.org/10.1007/s00376-018-7273-9

Publisher: Science Press, co-published with Springer

All outputs in CentAUR are protected by Intellectual Property Rights law, including copyright law. Copyright and IPR is retained by the creators or other copyright holders. Terms and conditions for use of this material are defined in the End User Agreement. 


\section{www.reading.ac.uk/centaur}

\section{CentAUR}

Central Archive at the University of Reading

Reading's research outputs online 


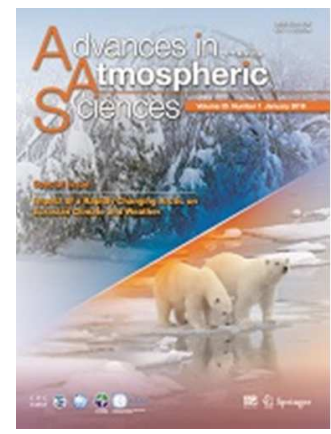

The effect of horizontal resolution on the representation of the global monsoon annual cycle in Atmospheric General Circulation Models

\begin{tabular}{|c|c|}
\hline Journal: & Advances in Atmospheric Sciences \\
\hline Manuscript ID & AAS-2017-0273.R1 \\
\hline Manuscript Type: & Special Issue: CSSP (Submission deadline: 31 Oct. 2017) \\
\hline $\begin{array}{r}\text { Date Submitted by the } \\
\text { Author: }\end{array}$ & $\mathrm{n} / \mathrm{a}$ \\
\hline Complete List of Authors: & $\begin{array}{l}\text { Zhang, Lixia; IAP, LASG } \\
\text { ZHOU, Tian-Jun; IAP, LASG } \\
\text { Klingaman, Nicholas; University of Reading, National Centre for } \\
\text { Atmospheric Science and Department of Meteorolog } \\
\text { Wu, Peili; Met Office, Hadley Centre } \\
\text { Roberts, Malcolm J.; Met Office, Hadley Centre }\end{array}$ \\
\hline
\end{tabular}


2 The effect of horizontal resolution on the representation of the global monsoon annu-

4 Lixia Zhang ${ }^{1,2}$, Tianjun Zhou ${ }^{1}$, Nicholas P. Klingaman ${ }^{3}$, Peili $\mathrm{Wu}^{4}$, Malcolm Roberts ${ }^{4}$ 5

$6{ }^{1}$ LASG, Institute of Atmospheric Physics, Chinese Academy of Sciences, Beijing, China

$7{ }^{2}$ Collaborative Innovation Center on Forecast and Evaluation of Meteorological Disasters,

8 Nanjing University of Information Science \& Technology, Nanjing, China

$9{ }^{3}$ National Centre for Atmospheric Science and Department of Meteorology, University of

10 Reading, Reading, United Kingdom

11 4. Met Office Hadley Centre, Exeter, United Kingdom Beijing 100029, China. Phone: 86-10-8299-5452 


\section{Abstract}

26 The sensitivity of the representation of the global monsoon annual cycle to horizontal 27 resolution is compared in three Atmospheric General Circulation Models (AGCMs): the 28 Met Office Unified Model-Global Atmosphere 3.0 (MetUM-GA3), the Meteorological Research Institute AGCM3 (MRI-AGCM3) and Global High Resolution AGCM from the Geophysical Fluid Dynamics Laboratory (GFDL-HiRAM). For each model, we use two 31 horizontal resolution configurations for the period 1998-2008. Increasing resolution 32 consistently improves simulated precipitation and low-level circulation of the annual mean 33 and the first two annual cycle modes, as measured by pattern correlation coefficient and 34 Equitable Threat Score. Improvements in simulating the summer monsoon onset and withdrawal are region-dependent. No consistent response to resolution is found in simulating summer monsoon retreat. Regionally, increased resolution reduces the positive 37 bias in simulated annual mean precipitation, the two annual-cycle modes over the West 38 African monsoon and Northwestern Pacific monsoon. An overestimation of the solstitial 39 mode and an underestimation of the equinoctial asymmetric mode of the East Asian 40 monsoon are reduced in all high-resolution configurations. Systematic errors exist in 41 lower-resolution models for simulating the onset and withdrawal of the summer monsoon. 42 Higher resolution models consistently improve the early summer monsoon onset over East 43 Asia and West Africa, but substantial differences exist in the responses over Indian 44 monsoon region, where biases differ across the three low-resolution AGCMs. This study 45 demonstrates the importance of a multi-model comparison when examining the added 46 value of resolution and the importance of model physical parameterizations for the Indian 47 monsoon simulation.

48 Key Words : global monsoon, high resolution modeling, annual cycle, AMIP 


\section{Introduction}

Monsoons are characterized by a seasonal wet-dry contrast and a reversal of prevailing winds, due to the reversal of land-sea and inter-hemispheric thermal contrasts forced by the annual cycle of solar heating. The global monsoon is a dominant mode of annual variability of the global tropical circulation and is a response of the coupled climate system to annual variations in solar forcing (Wang and Ding 2008). Global monsoon regions sustain nearly two-thirds of the world's population and support some of the largest and fastest growing urban areas. The simulation and prediction of the annual cycle of monsoon circulation and precipitation is critically important, because of the effect of monsoons on hydrology, agriculture and local livelihoods and economies.

Although global monsoon regions are connected through mass conservation (Trenberth et al. 2000), each regional monsoon has unique characteristics due to the local interactions among the land surface, ocean, convection and synoptic weather systems, especially over Asian-Australian monsoon region. The well-recognized Asian summer monsoon system typically first onsets over the Bay of Bengal (BoB) in early May, followed by the South China Sea in mid-May and then India in early June (Wu and Zhang 1998; Xu and Chan 2001; Mao and $\mathrm{Wu} 2007)$. The onset over the $\mathrm{BoB}$ is often preceded by the development of a monsoon onset vortex (Krishnamurti and Ramanathan 1982; Wu et al. 2012). A numerical study by Liu et al. (2002) demonstrated that the onset of South China Sea monsoon is due to a Rossby wave train triggered by the strong latent heating during the BoB monsoon onset. The seasonal march of the East Asian summer monsoon (EASM) displays a stepwise northward and northeastward advance. From early May to mid-May, the ridge line of the western Pacific subtropical high (WPSH) is located along $15^{\circ} \mathrm{N}$, and southern China experiences a pre-monsoon rainy season. Later, the WPSH exhibits two northward jumps in June and July with the ridge line located at $20^{\circ} \mathrm{N}$ and $25^{\circ} \mathrm{N}$, respectively, the monsoon 
74 rain band extends abruptly from the Indochina Peninsula - the South China Sea - from the 75 Philippines to the Yangtze River valley in early to mid-June, and the Meiyu (or Baiu in Japan and Changma in Korea) begins. The monsoon penetrates into northern China (34$41^{\circ} \mathrm{N}$ ) in mid-July, and the monsoon rainy season there lasts for one month and ends in early-middle August (Zhou et al. 2009). For the Australian summer monsoon onset in December, there are four major contributing factors, including land-sea thermal contrast, barotropic instability, arrival of the Madden-Julian oscillation (MJO) and intrusion of a midlatitude trough (Hung and Yanai 2004). The mean onset of the summer monsoon over West Africa is 24th June, which is linked to an abrupt latitudinal shift of the Inter-Tropical Convergence Zone (ITCZ) from a quasi-stationary location at $5^{\circ} \mathrm{N}$ in May-June to another quasi-stationary location at $10^{\circ} \mathrm{N}$ in July-August (Sultan and Janicot 2003). For American summer monsoon, the northward rainbelt movement over southwestern North America from mid-to-late June is associated with the northward progression of the ITCZ (Yu and Wallace 2000; Higgins and Shi 2001), while the onset of South American monsoon is related to eastward displacement of the South Atlantic subtropical high; it is also affected by intraseasonal variability through low-frequency trough or ridge occurrence over southern Brazil (Raia et al. 2008). The unique features of regional monsoons and their onset have been rigorous metrics for gauging climate models' performances.

The complexity of monsoon systems presents great challenges to simulate the climatological seasonal means and annual cycles of the monsoon (Sperber et al. 2013; Zhou et al. 2017), although substantial efforts have been made to improve model physics and dynamics in the past several decades. Model biases in the simulation of the monsoons limit the fidelity of monsoon predictions and projections (Dong et al. 2016). Sperber et al. (2013) evaluated the performance of 25 coupled climate models from Coupled Model Intercomparison Project Phase 5 (CMIP5) and 22 models from CMIP Phase 3 (CMIP3) in simulat- 
99

100

101

102

103

104

105

106

107

108

109

110

111

112

113

114

ing the Asian summer monsoon onset and retreat. The authors found an overall delayed onset over India in models, even though CMIP5 models showed improved fidelity relative to CMIP3. The onset and retreat definition in Sperber et al. (2013) was based on rainfall thresholds; monsoon onset might not occur in models, or may be delayed relative to observations, because of systematic dry biases. To avoid this issue, Sperber and Annamalai (2014) proposed a fractional accumulation method to evaluate the monsoon annual cycle; this method can be applied to many monsoon domains. The authors also found some systematic errors in the phase of rainfall annual cycle: coupled climate models in CMIP5 have delayed onsets of summer rainfall over India, the Gulf of Guinea, and South America, but early onsets for the Sahel and the North America.

Several studies have proposed techniques to improve monsoon simulation, including increasing horizontal resolution to capture more realistic large-scale atmospheric circulations and precipitation distributions (Hack et al. 2006; Roberts et al. 2009; Demory et al. 2014 ;

Berckmans et al. 2013). The added value of resolution in GCMs has been widely verified for many aspects of monsoon simulation (Kitoh et al., 2008; Mizuta et al., 2012; Johnson et al., 2016). For example, an examination of version 5.1 of the National Center for Atmospheric Research Community Atmosphere Model (CAM5) at three resolutions showed a much better representation of the intensity-frequency structures of precipitation in steepterrain regions over East Asia (Li et al. 2015). Higher resolution in CAM5 also improves the simulation of East Asian summer monsoon rain belt (Yao et al. 2017). Most investigations of the benefits of increased resolution were based on one model, however the sensitivity to resolution may differ among models. Ogata et al. (2017) showed that the MRIAGCM3 and the MetUM-GA3 produced less precipitation over the western Pacific with increasing resolution, but their sensitivity of Indian Ocean precipitation to resolution differed. Zhang et al. (2017) compared three AGCMs, each with two resolution configura- 
124 tions, and showed the sensitivity of monsoon precipitation to resolution varied greatly

125 among the models. To understand what aspects of resolution sensitivity are common

126 among AGCMs, it is important to compare several AGCMs using the same metrics. Given

127 the social and scientific importance of the onset and cessation of monsoon precipitation to

128 local livelihoods and economies, it is desirable to find whether high resolution systemati-

129 cally improves the representation of monsoon onset and withdrawal. This is the major mo-

130 tivation of the current study.

131 The remainder of the paper is organized as follows. The model simulations, validation

132 data and evaluation metrics are described in section 2. The improvement of high resolution

133 in simulating the annual cycle modes and summer monsoon onset and withdrawal are as-

134 sessed in section 3 and 4, respectively. Section 5 presents the summary and discussion.

135 2. Models, data and method description

1362.1 Model simulations and observational validation datasets

137 We use daily precipitation and monthly wind data from simulations with three AGCMs, 138 MetUM-GA3, MRI-AGCM3 and GFDL-HiRAM, each with two resolution configurations

139 for the period 1998-2008. Details of the models and experiments can be found in Table 1.

140 The model outputs of GFDL-HiRAM and MRI-AGCM3 were obtained from the Coupled

141 Model Intercomparison Project phase 5 data archive (Taylor et al., 2012). The simulations

142 of MetUM-GA3 are from the UPSCALE (UK on PRACE: weather-resolving Simulations

143 of Climate for globAL Environmental risk) project (Mizielinski et al., 2014). There are

144 very few different physical and dynamical settings in the MetUM-GA3 high-resolution

145 configuration compared to its low-resolution counterparts, mostly related to numerical 146 stability (Table 2 in Mizielinski et al. 2014). There are no physical parameter adjustments

147 between the MRI-AGCM3-2H and MRI-AGCM3-2S (Endo et al. 2012; Kusunoki 2016).

148 In GFDL-HiRAM, the shallow convective scheme and cloud microphysics are changed in 
149 C360 from C180 (Zhao et al. 2009; Chen and Lin 2012). We analyze the ensemble mean of

150 all realizations of each model. Because of the large inter-model differences in dynamical 151 cores and physics, it is hard to compare the resolution sensitivity across models. To ex152 clude the impact of model dependence and focus more on resolution, we compared the 153 high- and low-resolution configurations of the each model in this study.

154 The observed daily precipitation datasets used in this study include (1) Tropical Rainfall 155 Measuring Mission (TRMM) 3B42 V7 (Huffman et al. 2007), to evaluate the climatologi156 cal mean state of global monsoon precipitation, at $0.25^{\circ} \times 0.25^{\circ}$ resolution; and (2) Global 157 Precipitation Climatology Project V1.2 (GPCP), with a resolution $1.0^{\circ} \times 1.0^{\circ}$ (Adler et al. 158 2003). In addition, monthly wind data from Climate Forecast System Reanalysis (CFSR; 159 Saha et al. 2010) with a resolution of $0.5^{\circ} \times 0.5^{\circ}$ and from National Centers for Environmen160 tal Prediction-National Center for Atmospheric Research (NCEP-NCAR) reanalysis with 161 a resolution $2.5^{\circ} \times 2.5^{\circ}$ (Kalnay et al. 1996) are used as the circulation datasets. All datasets 162 are interpolated to the N216 resolution of MetUM-GA3 (approximately $1630.83^{\circ}$ longitude $\times 0.55^{\circ}$ latitude) using a distance-weighted interpolation method, to facilitate 164 comparison. The longest common period of 1998-2008 covered by all simulations and ob165 servations is selected in the following analysis.

\section{$166 \quad 2.2$ Evaluation metrics on global monsoon annual cycles}

167 In this study, two aspects of the annual cycle of the global monsoon are evaluated: (1)

168 the mean climate and annual cycle modes and (2) monsoon onset and withdraw. As pro169 posed by Wang and Ding (2008), the annual mean, the solstitial (symmetric) and equinoc170 tial (asymmetric) modes of the annual cycle, and the global monsoon domain can be used 171 as metrics to gauge model performance for simulating the mean climate and annual cycle.

172 The solstitial mode is represented by the differences in precipitation or circulation between 
173 June-September and December-March means; the equinoctial asymmetric mode is repre-

174 sented by the differences between April-May and October-November. The global monsoon

175 domain is delineated both by the monsoon precipitation index (MPI) and zonal westerly 176 wind index (MWI). MPI is defined as the annual range of precipitation normalized by its 177 annual mean. MWI is similar, but using $850 \mathrm{hPa}$ zonal wind (U850). The monsoon precipi178 tation domains are the areas where the annual range of precipitation exceeds $300 \mathrm{~mm}$ and 179 MPI exceeds 0.5, whereas monsoon wind domains are defined as WMI exceeding 0.5 180 without any restriction on the magnitude of annual range. The Annual range is the differ181 ence between May-September (MJJAS) and November-March (NDJFM) means in the

182 Northern Hemisphere, or NDJFM minus MJJAS in the Southern Hemisphere.

183 Previous studies have proposed several definitions of monsoon onset and withdrawal.

184 The commonly used definition is threshold-based (Wang and Lin 2002). One of the weak185 nesses of the threshold-based techniques is that monsoon onset might be delayed or accel186 erated by dry or wet biases, respectively, in the model, even though the model may have a 187 realistic annual cycle amplitude (Sperber et al. 2013; Sperber and Annamalai 2014). Mod188 els with dry biases are especially at a disadvantage since the observed threshold for defin189 ing monsoon may never be reached in such models, including MetUM-GA3 in this study 190 (Bush et al. 2015; Johnson et al. 2016). Since the biases differ among the three models 191 used here, it is important to find a relatively fair way to evaluate onset and withdrawal in 192 models. Thus, a fractional accumulation approach is employed here. The monsoon onset 193 and withdrawal are defined as the pentad when the fractional accumulation first be194 comes $>=0.2$ and $>=0.8$, respectively (Sperber and Annamalai 2014). The fractional accu195 mulated precipitation in a given pentad is the accumulated rainfall at that pentad divided by 196 the total accumulated rainfall at the end of the year. In this study, the pentads for the 
197 Southern African, Australian and South American domains have been reordered to run 198 from July 2 to June 27.

199 To quantitatively show the sensitivity of the simulated monsoon domain to resolution, 200 the Equitable Threat Score (ETS, Jolliffe and Stephenson 2003) is used in this study to 201 measure the simulation skill of the monsoon domain, which can be evaluated as a binary 202 event.

$203 \quad \mathrm{ETS}=(\mathrm{a}-\mathrm{ar}) /(\mathrm{a}+\mathrm{b}+\mathrm{c}-\mathrm{ar})$

204 where $a r=(a+b)(a+c) / n$, represents the skill of a random prediction. $a, b$, and $c$ are the 205 counts of hits, false alarms and misses of monsoon domain, respectively, and $\mathrm{n}$ is the 206 number of model gridpoints in the region $\left(45^{\circ} \mathrm{S}-45^{\circ} \mathrm{N}\right)$. The definition of each variable in 207 equation (1) can be found in Table 2. ETS ranges from 0 to 1 with perfect score of 1.

208 3. Annual mean and annual cycle modes

209 To investigate whether the improvement from higher-resolution is consistent across 210 the three models, we analyze the biases in the lower-resolution configuration and the dif211 ferences between the high- and low- resolution configurations. The bias in simulated an212 nual mean precipitation and improvements from higher resolution are presented in Fig. 1. In 213 observations (blue lines in left panel of Fig.1), substantial precipitation falls in the Indo214 Pacific warm pool $\left(60^{\circ} \mathrm{E}-180^{\circ}\right)$, ITCZ and South Pacific Convergence Zone (SPCZ). In 215 general, the observed centers are well captured by the low-resolution configuration of each 216 AGCM, with an overall positive bias over most of the tropics (blue lines in right panel of 217 Fig.1). In contrast, there are several common biases among the three low-resolution 218 AGCMs, including overestimations over the southwest Indian Ocean, SPCZ, northern edge 219 of the ITCZ, and Northwestern Pacific Ocean, with underestimations over the southeastern 220 Indian Ocean (Fig.1 a, c, e). Unique biases in each AGCM are also found, particularly in 
221 MetUM-GA3 N216, which underestimates Indian and Maritime Continent precipitation

222 (Fig.1a). A positive bias over the western central Pacific $\left(5^{\circ} \mathrm{S}-5^{\circ} \mathrm{N}, 120^{\circ} \mathrm{E}-180^{\circ}\right)$ is seen in MRI-AGCM3-2H, while negative biases are present in MetUM-GA3 N216 and GFDLHiRAM-C180. A consistent response to higher resolution among the three models is suppressed precipitation over the north of Maritime Continent (MC) and western Pacific $\left(5^{\circ} \mathrm{S}-\right.$ $\left.15^{\circ} \mathrm{N}, 120^{\circ}-160^{\circ} \mathrm{E}\right)$, which partly reduces the wet bias over the Northwestern Pacific $\left(5^{\circ}-\right.$ $15^{\circ} \mathrm{N}, 120^{\circ}-160^{\circ} \mathrm{E}$ ) in the three low-resolution models. This consistent response to finer 228 resolution also has been illustrated by Ogata et al. (2017), which compared MetUM-GA3 229 and MRI-AGCM3. This is further verified with one additional model, GFDL-HiRAM. As 230 suggested by Ogata et al. (2017) and Johnson et al. (2016), the reduced precipitation over 231 the north of MC and western Pacific may be related to better-resolved steep topography 232 over MC and Indochina, with moisture convergence and precipitation on the windward 233 side of the orography, which leads to decreased moisture availability on the leeward side in 234 summer and reduced precipitation over the north of MC and western Pacific. This can be 235 partly seen from the difference between higher- and lower-resolution models in simulating 236 the solstitial mode in Fig.2. Note that the low-resolution of both MetUM-GA3 and GFDL237 HiRAM underestimate the precipitation over MC, and the consistent response to resolution 238 makes this dry bias even worse.

239 As in Fig. 1, the biases in low-resolution models and improvement in higher- resolu240 tion configurations for the solstitial mode are shown in Fig. 2. The observed spatial pattern 241 shows an asymmetric contrast, with positive centers in Northern Hemisphere monsoon re242 gions (Indian-Pacific-East Asia, West Africa and northeast tropical Pacific $\left(5^{\circ}-20^{\circ} \mathrm{N}, 120^{\circ}-\right.$ $\left.24360^{\circ} \mathrm{W}\right)$ ) and negative centers in Southern Hemispheric monsoon regions (South Africa, 244 Australia and South America; lines in left panel of Fig.2). The centers are well reproduced 245 by all low-resolution models, but all show underestimations over East Asia, the northeast 
tropical Pacific, South Africa and Australia region and overestimations over the northwest

247 Pacific (shading in left panel of Fig.2). Higher resolution reduces this consistent simulation bias, particularly over the northwest Pacific and northeast tropical Pacific (shading in left panel of Fig.2). The improvement, however, is far smaller than the low-resolution model

250 bias. The biases in the three low-resolution models differ greatly over the Indian monsoon 251 region, where the solstitial mode is dramatically smaller than observation in MetUM-GA3 252 N216, greater in MRI-AGCM3-2H, and close to observation in GFDL-HiRAM-C180. The sensitivity of the solsticial mode in each model to resolution also differs over the Indian

254 monsoon region. The inconsistency of model biases and sensitivity to resolution indicate

255 the strong role for sub-grid scale physical parameterizations for simulating the Indian mon256 soon precipitation.

The biases in the simulated equinoctial asymmetric mode of the annual cycle and corresponding improvements in high-resolution models are shown in Fig. 3. In observations, 259 negative values are centered in the zonal belt along $\left(10^{\circ} \mathrm{N}-20^{\circ} \mathrm{N}\right)$, while positive values are 260 centered to its south $\left(0^{\circ}-10^{\circ} \mathrm{N}\right)$ and in Southeast China. The centers over the Pacific repre261 sent the asymmetric location of the spring and fall ITCZ (Wang and Ding 2008). The posi262 tive values over Southeast China shows the region's characteristic spring-persistence sea263 son in April and May ( $\mathrm{Li}$ et al. 2017). All low-resolution models capture the asymmetric 264 pattern of spring and fall precipitation, but a systematic overestimation over the Northern 265 Hemisphere is seen in all models, with negative biases north of the observed negative cen266 ter and positive biases near the observed positive centers. Positive biases over West Africa 267 are found in all low-resolution models. In high-resolution models, the overestimation over 268 Northwestern Pacific, West Africa and Southeast China is suppressed in all models; consis269 tent improvements are also found over the southern Maritime Continent. This indicates 270 increased resolution improves simulated precipitation in transition seasons. 
To quantify the improvement in high-resolution models, the pattern correlation coef-

272 ficient (PCC) and root-mean-square-error (RMSE) of simulated precipitation over $\left(45^{\circ} \mathrm{S}-\right.$ $45^{\circ} \mathrm{N}$ ) against TRMM are shown in Fig. 4 a,d,g. The simulated $850 \mathrm{hPa}$ winds for the an274 nual mean and the first annual cycle modes against CFSR reanalysis are also presented in 275 Fig.4. We compare the metrics for GPCP against TRMM and for NCEP-NCAR against 276 CFSR to show the observational uncertainty. In general, all low-resolution models simu277 late well the observed precipitation and $850 \mathrm{hPa}$ wind patterns. For example, the PCCs 278 (RMSEs) of simulated annual mean precipitation and $850 \mathrm{hPa}$ zonal (U850) and meridio279 nal wind (V850) in low resolution models (blue markers in Fig.4a-c) range from 0.85 to $2800.90(1.2$ to $1.6 \mathrm{~mm} /$ day $), 0.97$ to $0.99(0.75$ to $1.2 \mathrm{~m} / \mathrm{s})$ and 0.88 to $0.94(0.47$ to $0.60 \mathrm{~m} / \mathrm{s})$, 281 respectively, which are close to those PCCs for GPCP and NCEP-NCAR against TRMM 282 and CFSR, respectively. The PCCs increase consistently in all three high-resolution models 283 (red markers) compared with their low-resolution counterparts (blue markers) for the three 284 annual-cycle metrics. However, the model bias as demonstrated by RMSE appears insensi285 tive to increasing resolution. The PCCs of annual precipitation, U850, V850 simulated by 286 high-resolution models are systematically shifted to right of the low-resolution ones, in287 creasing to $0.95 \sim 0.97$, nearly 1.0 and $0.96 \sim 0.98$, respectively. The PCCs in high-resolution 288 models are even higher than PCCs of GPCP/NCEP-NCAR, although the RMSEs in these 289 simulations are far larger than the reanalysis. The same results are also found in the first 290 two leading modes. High resolution aids in representing details of precipitation and circula291 tion distributions, but not in reducing model biases.

292 Following the global monsoon domain definition proposed by Wang and Ding (2008), 293 the distributions of precipitation annual range and monsoon domain based on precipitation 294 are obtained and shown in Figure 5. In TRMM, the monsoon systems are well depicted by 295 this definition, including the Asian-Australian monsoon, the North and South African 
monsoons, and the North and South American monsoons (Fig.5a). The domain obtained 297 from GPCP is similar to TRMM except at the edges, particularly over the northern edge of 298 the northwestern Pacific monsoon region and the southern edge of the southwestern Indian 299 Ocean monsoon region, where the domain areas are relatively larger in GPCP than in 300 TRMM. The North American monsoon region $\left(120^{\circ} \mathrm{W}-60^{\circ} \mathrm{W}, 0^{\circ}-20^{\circ} \mathrm{N}\right)$ in all low301 resolution models is smaller and the western boundary is about 30 degrees eastward shifted 302 relative to observations, while the simulated northwestern Pacific monsoon is wider and 303 stronger than observations (left column in Fig.5). With increased resolution, the northwest304 ern Pacific monsoon region shrinks relative to the low-resolution models, particularly for 305 MRI-AGCM3, which extends to $170^{\circ} \mathrm{W}$ in MRI-AGCM3-2H but only to $170^{\circ} \mathrm{E}$ in MRI306 AGCM3-2S. Each model has unique biases, such as the absence of the Indian monsoon 307 region in MetUM-GA3 N216 due to its dry bias in India, a westward extended West Afri308 can monsoon $\left(60^{\circ} \mathrm{W}-60^{\circ} \mathrm{E}, 0^{\circ}-20^{\circ} \mathrm{N}\right)$ in MetUM-GA3 N216 and MRI-AGCM3-2H due to a 309 wider and stronger ITCZ over the Atlantic Ocean, and an unrealistic monsoon region over 310 the southern tropical Atlantic Ocean in MRI-AGCM3-2H and GFDL-HiRAM-C180. 311 Those biases remain in their high-resolution counterparts, indicating little influence of res-

312 olution increase. Similar analysis of the global monsoon domain based on U850 revealed 313 no obvious improvements from increased resolution (Figure not shown).

314 To quantitatively show the sensitivity of the simulated monsoon domain to resolution, 315 the Equitable Threat Score (ETS, Jolliffe and Stephenson 2003) for global and individual 316 regional monsoon domains was computed, using precipitation and U850 (Figure 6). Gener317 ally, higher-resolution configurations show slightly increased ETS for global monsoon pre318 cipitation (wind): from 0.53 to 0.54 (0.63 to 0.67 ) in MetUM-GA3, 0.56 to 0.57 (0.68 to $3190.69)$ in GFDL-HiRAM and 0.58 to 0.62 (0.73 to 0.77$)$ in MRI-AGCM3 models, respec320 tively. The ETS of the three high-resolution models for regional monsoon precipitation 
321 domains are not always higher than their low-resolution counterparts. Consistent improve-

322 ments with resolution are shown only for the South African monsoon domain, with the 323 largest increase from 0.59 to 0.64 in MetUM-GA3. The ETS for regional monsoon wind 324 domains are all higher in the high-resolution configurations. Note that the ETS metrics of 325 U850 and precipitation are not correlated. The skill scores of U850 are higher than those of 326 precipitation for both global and regional monsoons. Even though the higher-resolution 327 models show increased ETS for U850 for all regional monsoons except the East Asian 328 monsoon, the ETS metrics for precipitation do not increase (e.g., for the Indian monsoon).

329 4. Monsoon onset and withdrawal

330 Cumulative rainfall, which is the sum of rainfall up to a given pentad, averaged over 331 each monsoon region is presented in Fig.7 to show the temporal characteristics of the rain332 fall and the model bias. A rapid increase in cumulative occurs in all monsoon regions. 333 However, the initial pentad for the rapid increase differs among regions, indicating dif334 ferent onset times in each region. For the Asian-Australian monsoon system, rapid precipi335 tation increase starts around pentad 30 in India, pentad 25 in Southeast Asia and East Asia, 336 and pentad 10 in Australia. Over the African and American monsoon systems, an onset is 337 observed in the pentad 30 in West Africa and North America, and pentad 5 in South Africa 338 and South America.

339 An overall overestimation of annual total precipitation is presented over all regional 340 monsoons except for India and Southeast Asia. For Indian monsoon, there is a large dispar341 ity among the models in simulated total rainfall. There is an obvious wet bias $(50 \%$ wetter 342 than TRMM) in MRI-AGCM3, a dry bias (50\% less than TRMM) in MetUM-GA3 343 AGCMs and a relatively small bias in GFDL-HiRAM (Fig. 7a). The biases over Southeast 344 Asia are similar to those over India, but with smaller magnitudes (Fig. 7b). The evolution 345 of precipitation accumulation shows that the bias is relatively small in the beginning of 
346 year, but starts to increase around the monsoon onset pentad.

347 The observed and simulated spatial distributions of monsoon onset are shown in 348 Fig.8. The monsoon onset is the pentad when fractional accumulation first becomes $>=0.2$ 349 (Sperber and Annamalai 2014). We also examined the distributions of monsoon onset de350 fined by Wang and Lin (2002), in which onset is determined as the first pentad with the 351 relative rainfall rate to January mean in $\mathrm{NH}$ and July in SH exceeds $5 \mathrm{~mm} \mathrm{~d}^{-1}$. This thresh352 old is never reached in MetUM-GA3 over India because of the systematic dry bias (Fig.1, 353 Fig. 2 and Fig.7a). However, India is defined as a monsoon region in MetUM-GA3 based 354 on the monsoon wind index (Figure not shown). Thus, it is reasonable to use the fractional 355 accumulation to define monsoon onset and withdrawal. To focus on monsoon regions, only 356 the distributions in the observed monsoon regions based on the monsoon precipitation in357 dex are shown here. In observations (Fig.8a-b), the onset pentad shows a gradual increase 358 from the equator to poleward, indicating later onset in the higher-latitude monsoon regions 359 in both hemispheres. In the $\mathrm{NH}$, the earliest onset is pentad 25 in early May over the 360 southern edge of the Northern Hemispheric monsoon region and South China, while in the $361 \mathrm{SH}$ the earliest onset is pentad 68 in early December over the northern edge of Southwest

362 Indian Ocean. The latest NH monsoon onset is at pentad 47 in mid-August over the north363 ern edge of the North American and West African monsoons (pentad 15 in mid-March 364 over the south edge of Australian monsoon in SH).

365 All models simulate well the spatial distribution of global summer monsoon onset. 366 However, all low-resolution models simulate earlier monsoon onsets than the two observed 367 datasets, such as over the East Asian, West Africa monsoon, North American and South 368 American monsoon. Specifically, the area with onset by pentad 25 (hereafter P25 area) 369 over the West African, North American and East Asian monsoons is broader than in the 370 observation. In the high-resolution models, the P25 area slightly shrinks over the East 
371 Asian and Western African monsoons, particularly apparent in MetUM-GA3. This differ372 ence is also seen in the observations, in which the P25 area in GPCP is larger than in 373 TRMM, potentially due to the different resolutions of two observed datasets. It indicates 374 that high resolution improves the spatial distribution of precipitation and the delineation of 375 the monsoon onset boundaries. In other monsoon regions, there are no clear advantages of 376 increased resolution.

377 As for the global monsoon onset, we compute distributions of monsoon withdrawal, 378 the pentad with fractional accumulation first becomes $>=0.8$, in simulations and observa379 tions (Fig. 9). The observed monsoon withdraws from higher latitudes toward the equatori380 al monsoon regions. In NH, the earliest withdrawal over East Asian monsoon is witnessed 381 at pentad 48 in late August; the latest is over the southern edge of the Northern Hemi382 spheric monsoon region at pentad 60 in late October. In the SH, the earliest is over South 383 Africa at pentad 14 in mid-March and the latest over northern edge of Australia at pentad 38430 in late June. The observed monsoon withdrawal patterns are well captured by all mod385 els, but with relatively later withdrawals over the Australian and North American mon386 soons by two pentads. There are no obvious differences between the low- and high387 resolution configurations, or between GPCP and TRMM. These results suggest monsoon 388 withdrawal is less sensitive to resolution than monsoon onset.

389 To quantitatively identify the improvements from higher resolution, the summer mon390 soon onset and withdrawal pentads averaged over each regional monsoon are shown in 391 Figure 10. In observations, TRMM shows (red dots in Fig. 10) that the monsoon onsets 392 (withdraws) at pentad 33 (52) over India, 30.5 (54) over Southeast Asia, 27.5 (49.5) over 393 East Asia, 7 (28.5) over Australia, 32.8 (53.5) over West Africa, 8.2 (27) over South Afri394 ca, 32.4 (56) over North America and 3.2 (27.2) over South America, respectively. Com395 pared with TRMM, the onset pentads of all regional monsoons except the Indian monsoon 
396 are systematically earlier in GPCP, the lower-resolution observational dataset, with the 397 largest difference of up to two pentads earlier in the West Africa monsoon. However, the 398 monsoon withdrawal dates from TRMM and GPCP are similar, with a maximum differ399 ence of 0.5 pentad. The difference between TRMM and GPCP may suggest that resolution 400 has greater impact on monsoon onset than on withdrawal. For all domains the model dis401 persion far exceeds the differences between TRMM and GPCP. Here, we use the onset and 402 withdrawal derived from TRMM as a reference due to its higher resolution than GPCP. 403 All models show earlier onsets over East Asia, West Africa, South Africa and North Amer404 ica. The results are consistent with Fig.8 and Fig.9. Specifically, the largest bias is about 4054.5 pentads in MRI-AGCM3-2H over East Asia, 4 pentads in GFDL-HiRAM-C180 over 406 West Africa, 2 pentads in GFDL-HiRAM-C360 over South Africa and 4.5 pentads in 407 GFDL-hIRAM-C360 over North America, respectively. Increased resolution consistently 408 delays the monsoon onset over East Asia and West Africa in all AGCMs, matching well 409 with the differences between TRMM and GPCP. However, these improvements from high 410 resolution are only one pentad at most, far less than the biases of the corresponding low411 resolution models ( $\leq 4.5$ pentad). A consistently slightly advanced onset in higher412 resolution models (1.5 pentad earlier at maximum over Southeast Asia) relative to their 413 lower-resolution counterparts is shown over Southeast Asia, Australia, South Africa, North 414 America and South America. For the Indian monsoon, both the biases of the lower415 resolution configurations and the improvement in the high-resolution configurations differ 416 greatly among the three AGCMs, indicating less resolution sensitivity of Indian monsoon 417 onset.

\section{5. Summary and discussion}

419 In this study, the resolution sensitivity of the annual cycle of the global monsoon is in420 vestigated in three AGCMs, MetUM-GA3, MRI-AGCM3 and GFDL-HiRAM. We com- 
421 pared output from MetUM-GA3 at N216 (90-km) and N512 (40-km), MRI-AGCM3-2H $422(60-\mathrm{km})$ and MRI-AGCM3-2S (20-km), and GFDL-HiRAM-C180 (65-km) and GFDL-

423

424

425

426

427 HiRAM-C360 (32-km). We found consistent and inconsistent responses across the three AGCMs to increasing resolution.

A summary plot about the model responses to horizontal resolution is presented in Fig.11. All low-resolution AGCMs are biased toward higher annual mean precipitation and stronger solstitial and equinoctial asymmetric modes. With increasing resolution, all AGCMs show consistent improvements in simulating the precipitation and low-level circulation of the annual mean and the first two annual cycle modes, as determined from the pattern correlation coefficient and ETS as denoted by red boxes in Fig.11. Regionally, higher pattern correlation coefficients are found in three high-resolution AGCMs for precipitation for the annual mean (ANN), solstitial mode (AC1) and the equinoctial asymmetric mode (AC2) for all regional monsoons, except the Australian (Aus) and North American monsoons (NAm). The inconsistent response to increased resolution across the three AGCMs over North American and Australian monsoons may be partly due to their small monsoon area.

We found that improvements in simulating the summer monsoon onset and withdrawal are regionally dependent. No consistent response to resolution is found in simulating monsoon withdrawal. A consistent improvement in simulating East Asian (EAs), Southeast Asian (SAs) and Western African (WAf) monsoon onset are shown across three AGCMs, by delaying the monsoon onset over EAs and WAf and advancing over SAs. A consistently weakened equinoctial asymmetric mode over EAs and WAf with increasing resolution is seen across the three models, reducing wet biases in the transition seasons. Thus, the summer monsoon onset pentad of the two regional monsoons is systematically delayed in all high-resolution models relative to their low-resolution counterparts. In contrast, the im- 
446 provements of monsoon onset over SAs are consistently advanced across three models.

447 Systematic errors and responses to resolution differ greatly across the three AGCMs for the 448 simulated Indian (India) North American (NAm) and South hemispheric regional mon449 soons (Aus, SAf, SAm), and the response to resolution differs across the three AGCM, in450 dicating the dependence of these regions on physical parameterizations. Nevertheless, 451 better representation on the Indian are shown in all three AGCMs.

452 Comparing the impact of resolution on the simulated regional monsoon precipitation 453 annual cycle, this study demonstrates the importance of resolution for the East Asian mon454 soon and West African monsoon where improved annual cycles are simulated in the three 455 AGCMs. The positive bias of AC2 over the West African monsoon region is caused by 456 overestimated precipitation in spring; in CMIP5 models, this bias has been linked to the 457 representation of African Easterly Waves (see Fig.6 in Martin and Thorncroft 2015). Both 458 the AMIP and historical simulations of CMIP5 show wet biases over northern Africa in 459 spring; this bias is significantly reduced in high-resolution models. A possible reason is 460 that the finer resolution weakens the excessive African Easterly wave activity over 461 northern Africa and thus reduces rainfall (Martin and Thorncroft 2015). Over the East 462 Asian monsoon region, the summer monsoon rainfall, particularly the Meiyu-Baiyu rain463 belt, is underestimated in many contemporary models (Kang 2004; Huang et al. 2013). 464 Therefore, the simulated contribution of summer rainfall to the annual total is also underes465 timated, resulting in relatively faster fractional accumulations of precipitation in spring and 466 earlier onset of EAs. As shown in Yao et al. (2017), as resolution increases, intensified nor467 therly flow over the central northern areas of China and southerly flow to the south of 468 Japan is found both from the AMIP simulations in CMIP5 and in CAM5 with different 469 resolutions. Those changes with resolution are related to the topography driven barotropic 470 Rossby waves downstream of the Tibetan Plateau (Yao et al. 2017). However, how the in- 
471 creased resolution affects the regional circulation remains inconclusive and deserves fur472 ther investigation.

473 Although several consistent responses to resolution are identified across the three 474 AGCMs considered, large differences still exist, especially over the Indian monsoon re475 gion. Large differences in the sensitivity to resolution over the Indian monsoon region 476 were found between MetUM-GA3 and MRI-AGCM3, particularly in synoptic and intra477 seasonal variability, such as monsoon low-pressure systems (Ogata et al. 2017). Those in478 consistencies across models demonstrate the importance of improving physical parameteri479 zations to reduce these systematic errors. This paper highlights the need for further multi480 model comparisons to determine the added value of horizontal resolution in climate simu481 lations.

483 Acknowledgements:

484 This work was jointly supported by the National Natural Science Foundation of China 485 under grant Nos. 41420104006 and 41330423, Program of International S\&T Cooperation 486 under grant 2016YFE0102400, and the UK-China Research \& Innovation Partnership 487 Fund through the Met Office Climate Science for Service Partnership (CSSP) China as part 488 of the Newton Fund. Nicholas P. Klingaman was funded by an Independent Research 489 Fellowship from the Natural Environment Research Council (NE/L010976/1). 
490 References:

491 Adler, R. et al. 2003: The version-2 global precipitation climatology project (GPCP) 492 monthly precipitation analysis (1979-present). J. Hydrometeorol. 4, 1147-1167.

493 Berckmans Julie, Tim Woollings, Marie-Estelle Demory, Pier-Luigi Vlidale, and Malcolm 494 Robserts, 2013: Atmospheric blocking in a high resolution climate model: influences of 495 mean state, orography and eddy forcing, Atmos. Sci. Let. 14: 34-40.

496 Chen J.H, S. J. Lin, 2012: Seasonal Predictions of Tropical Cyclones Using a 25-km497 Resolution General Circulation Model, Journal of Climate. 26:380-398.

498 Dong G., H. Zhang, A. Moise, L. Hanson, P. Liang, H. Ye, 2016: CMIP5 model-simulated 499 onset, duration and intensity of the Asian summer monsoon in current and future $500 \quad$ climate. Clim Dyn.,46:355-382.DOI 10.1007/s00382-015-2588-z

501 Donlon C. J., Martin M., Stark J., Roberts-Jones J., Fiedler E., and Wimmer W. 2012. The 502 Operational Sea Surface Temperature and Sea Ice Analysis (OSTIA) system, Remote 503 Sens. Environ., 116, 140-158, doi:10.1016/j.rse.2010.10.017.

504 Endo H, Kitoh A, Ose T, Mizuta R, Kusunoki S (2012) Future changes and uncertainties in 505 Asian precipitation simulated by multiphysics and multi-sea surface temperature 506 ensemble experiments with high-resolution Meteorological Research Institute 507 atmospheric general circulation models (MRI-AGCMs). J Geophys Res 117:D16118. 508 doi:10.1029/2012JD017874

509 Higgins R. W., and W. Shi, 2001: Intercomparison of the principal modes of interannual 510 and intraseasonal variability of the North American Monsoon System. J. Climate, 14, $511 \quad 403-417$

512 Huang, D. Q., J. Zhu, Y.-C. Zhang, and A.-N. Huang, 2013: Uncertainties on the simulated 
513 summer precipitation over eastern China from the CMIP5 models. J. Geophys. Res.

$514 \quad$ Atmos., 118, 9035-9047

515 Huffman G. J., D. T. Bolvin, E. J. Nelkin, D. B. Wolff, R. F. Adler, G. Gu, Y. Hong, K. P. 516 Bowman, and E. F. Stocker. 2007: The TRMM multisatellite precipitation analysis 517 (TMPA): Quasi-global, multiyear, combined-sensor precipitation estimates at fine 518 scales, J. Hydrometeorol., 8(1): 38-55.

519 Hung C.W, M. Yanai, 2004: Factors contributing to the Australian summer monsoon. 520 Q.J.R. Meteorol. Soc., 130: 739-758.

521 Johnson SJ et al 2016: The resolution sensitivity of the South Asian monsoon and Indo522 Pacific in a global $0.35^{\circ}$ AGCM. Clim Dyn., 46(3): 807-831

523 Jolliffe, I.T., and D.B. Stephenson, 2003: Forecast Verification: A Practitioner's Guide in 524 Atmospheric Science. Wiley, Hoboken, NJ, 240 pp.

525 Kang, I.-S., 2004: Current status of AGCM monsoon simulations. East Asian Monsoon, 526 C.-P. Chang, Ed., World Scientific, 301-331.

527 Kitoh A, Kusunoki S. 2008: East Asian summer monsoon simulation by a 20-km mesh 528 AGCM. Climate Dyn., 31: 389-401. doi:10.1007/s00382-007-0285-2.

529 Krishnamurti TN, Ramanathan Y (1982) Sensitivity of the monsoon onset to differential 530 heating. J Atmos Sci. 39(6):1290-1306

531 Kusunoki Shoji, 2016: Is the global atmospheric model MRI-AGCM3.2 better than the 532 CMIP5 atmospheric models in simulating precipitation over East Asia, Clim Dyn, doi: $533 \quad 10.1007 / \mathrm{s} 00382-016-3335-9$.

534 Li, J., R. Yu, W. Yuan, H. Chen, W. Sun, Y. Zhang. 2015: Precipitation over East Asia 
535 simulated by NCAR CAM5 at different horizontal resolutions. Journal of Advances in 536 Modeling Earth Systems, 7(2), 774-790. DOI 10.1002/2014MS000414

537 Li P., T. Zhou, X. Chen, 2017: Water vapor transport for spring persistent rains over 538 southeastern China based on five reanalysis datasets. Climate Dynamics, DOI $539 \quad 10.1007 / \mathrm{s} 00382-017-3680-3$

540 Liu Y. M., Chan J.C., Mao J. Y., Wu G. X., 2002: The role of Bay of Bengal convection in 541 the onset of the 1998 South China Sea summer monsoon. Mon Weather Rev, 130: 2731$542 \quad 2744$

543 Mao J.Y., Wu G.X., 2007: Interannual variability in the onset of the summer monsoon over 544 eastern Bay of Bengal. Theor Appl Climatol., 89:155-170

545 Martin E. R., and C. Thorncroft, 2015: Representation of African Easterly Waves in $546 \quad$ CMIP5 Models, J. Climate, 28, 7702-7715.

547 Mizielinski, M. S., M. J. Roberts, P. L. Vidale, R. Schiemann, M.-E. Demory, J. Strachan, 548 T. Edwards, A. Stephens, B. N. Lawrence, M. Pritchard, P. Chiu, A. Iwi, J. Churchill, 549 C. Del Cano Novales, J. Kettleborough, W. Roseblade, P. Selwood, M. Foster, M. 550 Glover, and A. Malcolm. 2014: High resolution global climate modelling; the 551 UPSCALE project, a large simulation campaign. Geosci. Model Dev., 7: 563-591.

552 Mizuta R, Yoshimura H, Murakami H, Matsueda M, Endo H, Ose T, Kamiguchi K, 553 Hosaka M, Sugi M, Yukimoto S, Kusunoki S, Kitoh A. 2012: Climate simulations 554 using MRI-AGCM3.2 with 20-km grid. J Meteor Soc Japan, 90A: 233-258. 555 doi:10.2151/jmsj.2012-A12

556 Ogata T., S. J. Jonhnson, R. Shiemann, M. Demory, R. Mizuta, K. Yoshida, O. Arakawa, 557 2017: The resolution sensitivity of the Asian summer monsoon and its inter-model 558 comparison between MRI-AGCM and MetUM. Clim Dyn, DOI 10.1007/s00382-016- 
560 Raia A., I. F. A. Cavalcanti, 2008: The life cycle of the South African monsoon system. Journal of Climate, 21: 6227-6246.

562 Rayner, N. A.; Parker, D. E.; Horton, E. B.; Folland, C. K.; Alexander, L. V.; Rowell, D. 563 P.; Kent, E. C.; Kaplan, A., 2003: Global analyses of sea surface temperature, sea ice, 564 and night marine air temperature since the late nineteenth century J. Geophys. Res. 108: 4407 10.1029/2002JD002670

566 Sperber KR, Annamalai H, Kang IS, Kitoh A, Moise A, Turner A, Wang B, Zhou T, 2013: 567 The Asian summer monsoon: an inter- comparison of CMIP5 vs. CMIP3 simulations of 568 the late 20th century. Clim Dyn 41: 2711-2744

569 Sperber K R, Annamalai H, 2014: The use of fractional accumulated precipitation for the 570 evaluation of the annual cycle of monsoons. Clim Dyn., 43: 3219-3244 DOI $571 \quad 10.1007 / \mathrm{s} 00382-014-2099-3$

572 Sultan B., S. Janicot, 2003: The West African Monsoon Dynamics. Part II: The "Pre573 onset" and "Onset" of the Summer Monsoon. Journal of Climate, 16: 3407-3427.

574 Trenberth K, Stepaniak D, and Caron J. 2000: The global monsoon as seen through the di575 vergent atmospheric circulation. Journal of Climate, 13(22): 3 969-3 993.

576 Wang B., H. Lin 2002: Rainy season of the Asian-Pacific summer monsoon. J Clim., 15: $577 \quad 386-398$

578 Wang B, Ding Q. 2008: Global monsoon: dominant mode of annual variation in the trop579 ics. Dyn Atmos Oceans, 44:165-183. doi:10. 1016/j.dynatmoce.2007.05.002

580 Wu G.X., Zhang Y.S. 1998: Tibetan Plateau forcing and the situating and timing of the 
582 Wu G. X., Guan Y., Liu Y.M., Yan J.H., Mao J.Y. 2012: Air-sea interaction and formation 583 of the Asian summer monsoon onset vortex over the Bay of Bengal. Clim Dyn., 38: $584 \quad 261-279$.

585 Xu J., Chan J.C. 2001: First transition of the Asian summer monsoon in 1998 and the ef586 fect of the Tibet: tropical ocean thermal contrast. J Meteor Soc Japan, 79: 241-253

587 Yao Junchen, Tianjun Zhou, Zhun Guo, Xiaolong Chen, Liwei Zou, Yong Sun, 2017: Im588 proved performance of High-Resolution Atmospheric Models in simulating the East589 Asian Summer Monsoon Rainbelt. Journal of Climate, in press.

590 Yu, B., and J. M. Wallace, 2000: The principal mode of interannual variability of the North 591 American Monsoon System. J. Climate, 13, 2794-2800.

592 Zhang L., P. Wu, T. Zhou, M. Roberts, R. Schiemann, 2016: Added value of high resolu593 tion models in simulating global precipitation characteristics. Atmospheric Science Let$594 \quad$ ters, 17: 646-657.

595 Zhao M., Isaac M. Held, Shian-Jiann Lin, and Gabriel A. Vecchi. 2009: Simulations of 596 Global Hurricane Climatology, Interannual Variability, and Response to Global Warm597 ing Using a 50-km Resolution GCM. J. Climate, 22: 6653-6678. doi: $598 \quad$ http://dx.doi.org/10.1175/2009JCLI3049.1

599 Zhou Tianjun, Xiaolong Chen, Bo Wu, Zhun Guo, Yong Sun, Liwei Zou, Wenmin Man, 600 Lixia Zhang, Chao He, 2017: A Robustness Analysis of CMIP5 Models over the East 601 Asia-Western North Pacific Domain, Engineering, 3(5), 773-778, 602 https://doi.org/10.1016/J.ENG.2017.05.018 
603 Zou, L. W., and T. J. Zhou, 2015: Asian summer monsoon onset in simulations and CMIP5

604 projections using four Chinese climate models. Adv. Atmos. Sci., 32(6): 794-806.

605 


\section{Figure Captions:}

607 Table 1 Model descriptions including model resolution, sea surface temperature (SST) 608 forcing, realization numbers and selected simulation years.

609 Table 2. Schematic contingency table for computing the ETS metric for model simulations 610 of the monsoon domain (after Table 3.1 in Jolliffe and Stephenson 2003)

611 Figure 1 Spatial distributions of the difference between low-resolution models and TRMM 612 (units: $\mathrm{mm} \mathrm{day}^{-1}$, left column) and between high and low resolutions of the same model 613 (units: $\mathrm{mm}^{\mathrm{day}}{ }^{-1}$, right column) in simulating annual mean precipitation. (a) MetUM614 GA3 N216 minus TRMM, (b) MetUM-GA3 N512 minus MetUM-GA3 N216, (c) MRI615 AGCM3-2H minus TRMM, (d) MRI-AGCM3-2S minus MRI-AGCM3-2H, (e) GFDL616 HiRAM-C180 minus TRMM, (f) GFDL-HiRAM-C360 minus GFDL-HiRAM-C180. 617 Blue lines in the left and right columns show the climatological mean precipitation from 618 TRMM and the low-resolution models, respectively. The hatched area denotes where 619 precipitation exceeds $7 \mathrm{~mm}$ day $^{-1}$.

620 Figure 2 As in Figure 1, but for the spatial distribution of the solstitial mode (unit: mm 621 day $^{-1}$ ), defined as the difference between June-September (JJAS) and December-March 622 (DJFM) mean precipitation. The blue and red lines indicate positive and negative val623 ues, respectively.

624 Figure 3 As in Figure 1, but for the equinoctial asymmetric mode defined as the difference 625 between April-May (AM) and October-November (ON) mean precipitation.

626 Figure 4 Scatter diagrams for the fidelity of simulated precipitation and $850 \mathrm{hPa}$ winds of 627 (a)-(c) annual mean, (d)-(f) solstitial mode, and (g)-(i) equinoctial asymmetric mode 628 against TRMM and CFSR. The abscissa and ordinate are the pattern correlation coeffi629 cients (PCC) and root-mean-square-error (RMSE), respectively. The fidelity of GPCP 630 and NCEP2 against TRMM and CFSR are also shown in dots to represent the observa- 
631 tional uncertainty. The stars, triangles and diamonds represent the results from MetUM632 GA3, MRI-AGCM3 and GFDL-HiRAM, respectively, with high-resolution models in 633 red and low-resolution in blue.

634 Figure 5 Climatological annual range of precipitation (shaded, units: mm day-1) and glob635 al monsoon domain (contours) derived from (a) TRMM, (b) GPCP, (c) MetUM-GA3 636 N216, (d) MetUM-GA3 N512, (e) MRI-AGCM3-2H, (f) MRI-AGCM3-2S, (g) GFDL637 HiRAM-C180, (h) GFDL-HiRAM-C360. The annual range is defined as the May to 638 September (MJJAS) minus November to March (NDJFM) mean precipitation for the 639 Northern Hemisphere, and NDJFM minus MJJAS for the Southern Hemisphere.

640 Figure 6. The ETS score of monsoon domain simulation over (a) global (GM), (b) Indian 641 (India), (c) Southeast Asia (SAs), (d) East Asian (EAs), (e) Australian (Aus), (f) West 642 African (WAf), (g) South African (SAf), (h) North American (NAm) and (i) South 643 American (SAm) monsoon. The abscissa (ordinate) is ETS scores of simulated domain 644 derived from precipitation (U850), respectively. The fidelity of GPCP against TRMM is 645 shown in dots. The fidelity of GPCP and NCEP2 against TRMM and CFSR are also 646 shown in dots to represent the observational uncertainty. The star, triangle and diamond 647 represent the results from MetUM-GA3, MRI-AGCM3 and GFDL-HiRAM, respective648 ly, with high-resolution models in red and low-resolution in blue.

649 Figure 7 Observed and simulated precipitation accumulations (unit: $\mathrm{mm}$ ) from the first 650 pentad to the end of year, and fractional accumulations (unit: \%) around the monsoon 651 onset pentad averaged over (a) Indian (India), (b) Southeast Asian (SAs), (c) East Asian 652 (EAs), (d) Australian (Aus), (e) West African (WAf), (f) South African (SAf), (g) North 653 American (NAm) and (h) South American (SAm) monsoon. Note: for Southern Hemi654 sphere locations (Australian, South African, and South American monsoons) the pen655 tads were reordered to July-June prior to the analysis. The black, red, blue and green 
656 lines represent the results of TRMM, MetUM-GA3, MRI-AGCM3 and GFDL-HiRAM, 657 respectively, with high-resolution configurations in solid lines and low-resolution con658 figuratiosn in dashed lines.

659 Figure 8 Climatological monsoon onset pentad derived from (a) TRMM, (b) GPCP, (c) 660 MetUM-GA3 N216, (d) MetUM-GA3 N512, (e) MRI-AGCM3-2H, (f) MRI-AGCM3661 2S, (g) GFDL-HiRAM-C180, (h) GFDL-HiRAM-C360. The monsoon onset pentad is 662 defined as the pentad when fractional accumulation first becomes $>=0.2$ (Sperber and 663 Annamalai 2014). Note: for Southern Hemisphere locations (Australian, South African, 664 and South American monsoon) the pentads were reordered to July-June prior to the $665 \quad$ analysis.

666 Figure 9 As in Figure 8, but for the monsoon withdrawal pentad, defined as the pentad 667 with fractional accumulation first becomes $>=0.8$ (Sperber and Annamalai 2014). Note: 668 for Southern Hemisphere locations (Australian, South African, and South American 669 monsoon) the pentads were reordered to July-June prior to the analysis.

670 Figure 10 The monsoon onset (x axis) and withdraw pentad (y axis) averaged over (a) In671 dian (India), (b) Southeast Asian (SAs), (c) East Asian (EAs), (d) Australian (Aus), (e) 672 West African (WAf), (f) South African (SAf), (g) North American (NAm) and (h) 673 South American (SAm) monsoon. Note: for Southern Hemisphere locations (Australian, 674 South African, and South American monsoon) the pentads were reordered to July-June 675 prior to the analysis. The dots, stars, triangles and diamonds represent the results from 676 the observations, MetUM-GA3, MRI-AGCM3 and GFDL-HiRAM, respectively, with 677 high-resolution configurations in red and low-resolution configurations in blue.

678 Figure 11 Improvement of the simulation on the annual cycle of global monsoon precipita679 tion with horizontal resolution. Red boxes indicate high-resolution consistently im680 proves performance across all three AGCMs; blue boxes indicate improvements with 
681 resolution are inconsistent; orange boxes indicate a better simulation is shown in all 682 three high-resolution AGCMs but the responses to resolution are inconsistent across 683 models. The values from left to right in each box are the difference between high- and 684 low-resolution configurations of MetUM-GA3, MRI-AGCM3 and GFDL-HiRAM, re685 spectively. The metric for the annual modes, including annual mean (ANN), solstitial 686 mode $(\mathrm{AC} 1)$, the equinoctial asymmetric mode $(\mathrm{AC} 2)$, is the pattern correlation coeffi687 cient with TRMM. The metrics for the monsoon domain and monsoon onset/withdrawal 688 are ETS and the onset/withdrawal pentad, respectively.

689 690 691 692 693 
694 Table 1. Model information description including model resolution, sea surface tem695 perature (SST) forcing, realization numbers and selected simulation years.

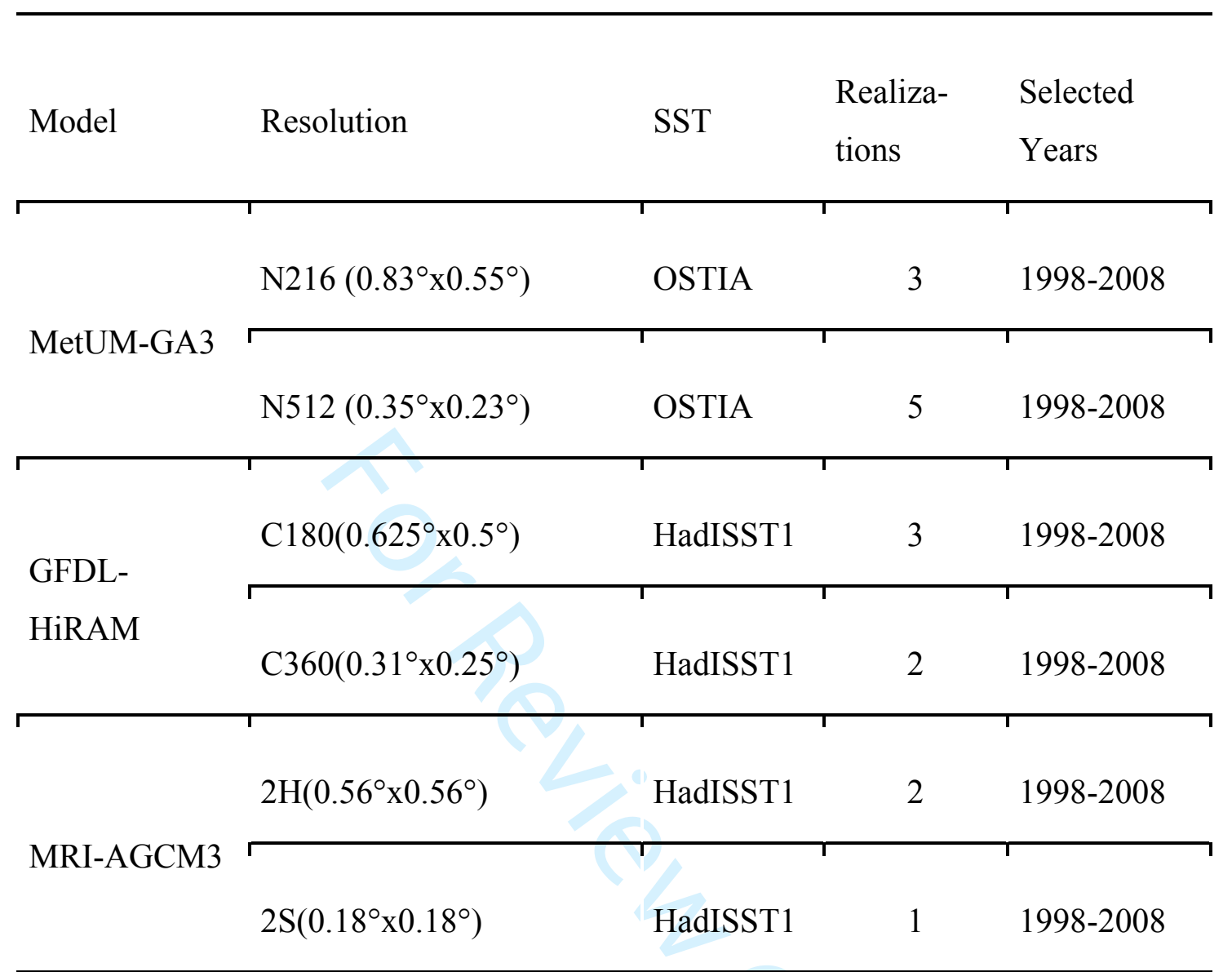

696

697

698 
699 Table 2. Schematic contingency table for computing the ETS metric for model 700 simulations of the monsoon domain (after Table 3.1 in Jolliffe and Stephenson 2003)

\section{Event Observed}

\begin{tabular}{cccc}
\hline Event Simulated & Monsoon domain & Non-monsoon domain & Total \\
\hline Monsoon domain & $\mathrm{a}$ (Hits) & $\mathrm{b}$ (False alarms) & $\mathrm{a}+\mathrm{b}$ \\
\hline Non-monsoon domain & $\mathrm{c}$ (Misses) & $\mathrm{d}$ (Correct rejections) & $\mathrm{c}+\mathrm{d}$ \\
\hline Total & $\mathrm{a}+\mathrm{c}$ & $\mathrm{b}+\mathrm{d}$ & $\mathrm{a}+\mathrm{b}+\mathrm{c}+\mathrm{d}=\mathrm{n}$ \\
\hline
\end{tabular}

701

702

703

704 
(a) MetUM N216 Minus TRMM

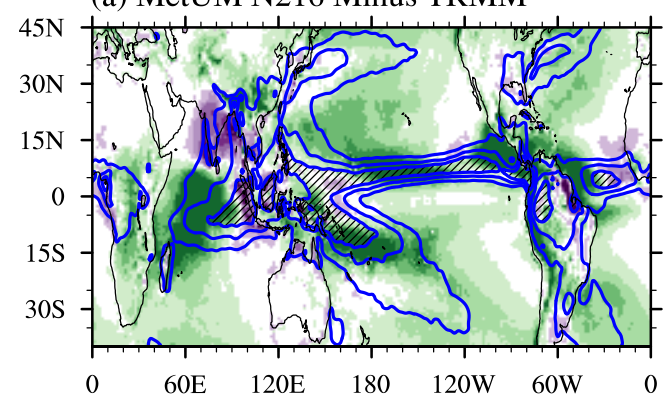

(c) MRI-AGCM3-2H Minus TRMM

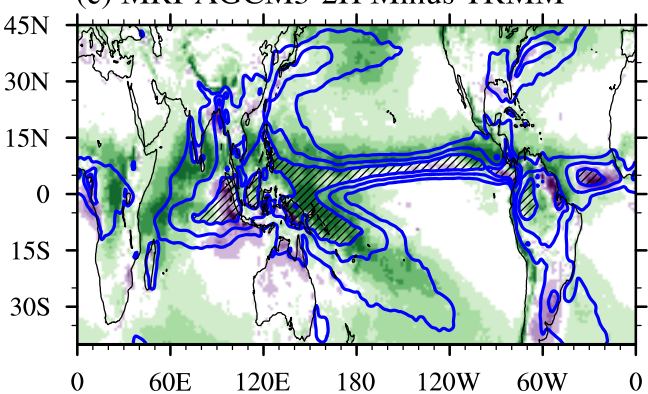

(e) GFDL-HiRAM-C180 Minus TRMM (b) MetUM (N512-N216)

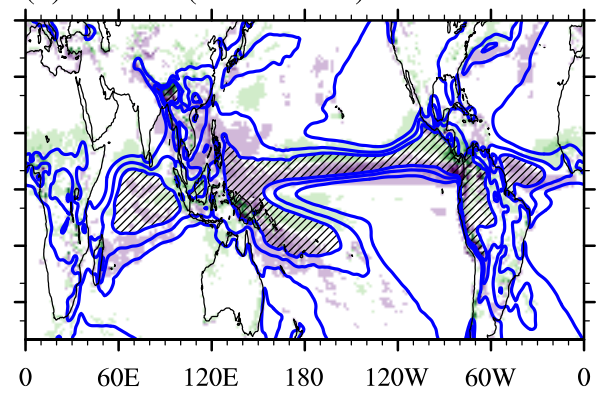

(d) MRI-AGCM3 (2S-2H)

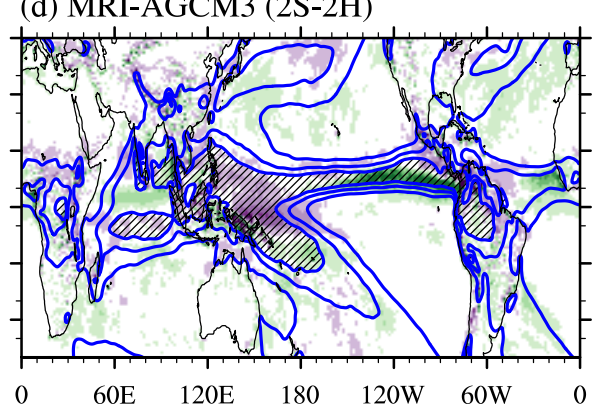

(f) GFDL-HiRAM (C360-C180)

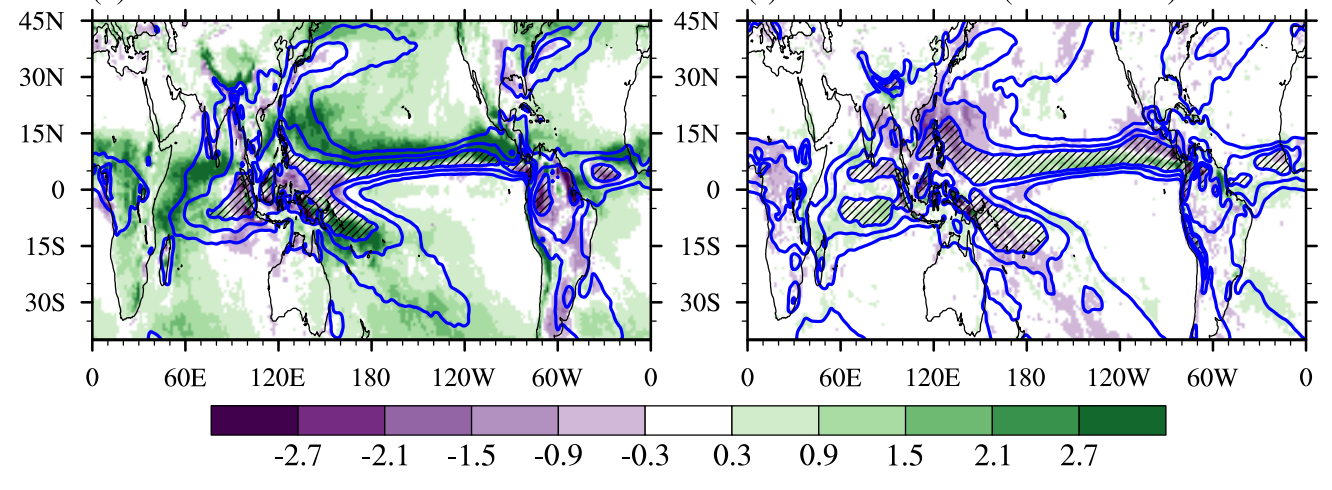

705

706 Figure 1 Spatial distributions of the difference between low-resolution models and TRMM

707 (units: $\mathrm{mm} \mathrm{day}^{-1}$, left column) and between high and low resolutions of the same model

708 (units: $\mathrm{mm} \mathrm{day}^{-1}$, right column) in simulating annual mean precipitation. (a) MetUM-GA3

709 N216 minus TRMM, (b) MetUM-GA3 N512 minus MetUM-GA3 N216, (c) MRI-

710 AGCM3-2H minus TRMM, (d) MRI-AGCM3-2S minus MRI-AGCM3-2H, (e) GFDL-

711 HiRAM-C180 minus TRMM, (f) GFDL-HiRAM-C360 minus GFDL-HiRAM-C180. Blue

712 lines in the left and right columns show the climatological mean precipitation from TRMM

713 and the low-resolution models, respectively. The hatched area denotes where precipitation

714 exceeds $7 \mathrm{~mm}$ day $^{-1}$.

715 
(a) MetUM N216 Minus TRMM

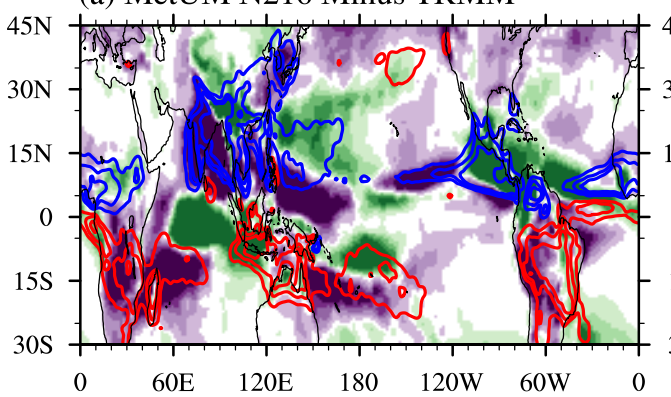

(c) MRI-AGCM3-2H Minus TRMM

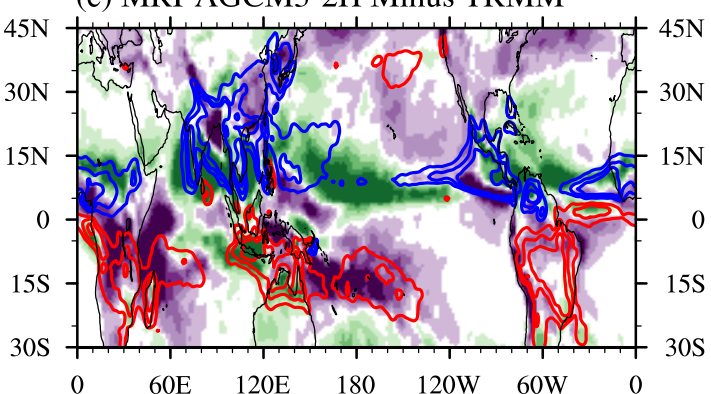

(e) GFDL-HiRAM-C180 Minus TRMM

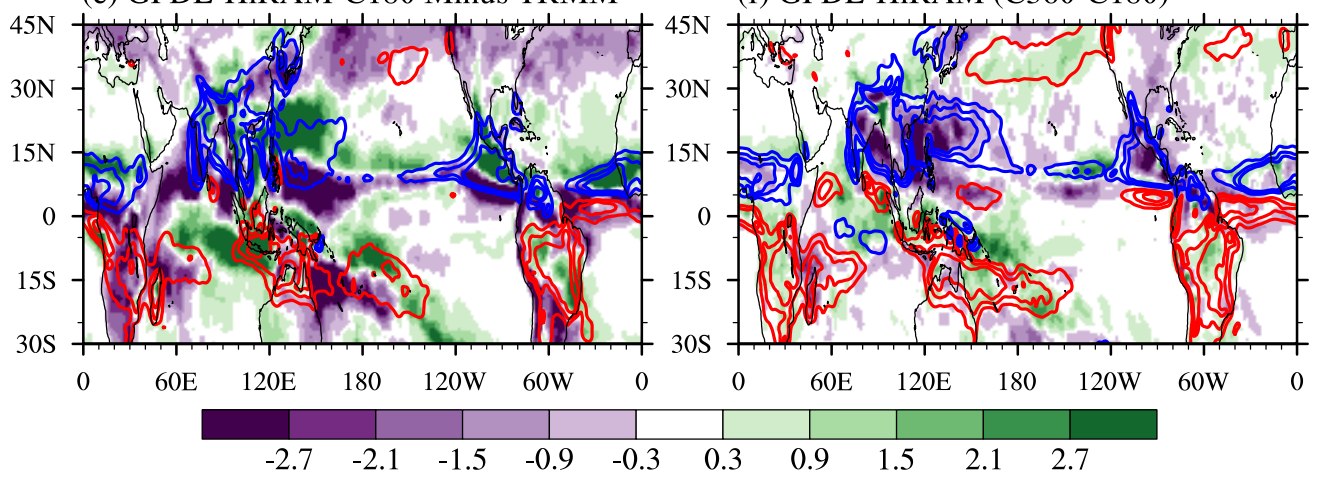

(b) MetUM (N512-N216)

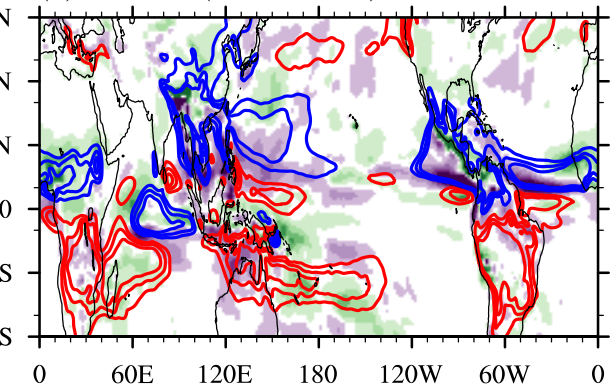

(d) MRI-AGCM3 (2S-2H)

(f) GFDL-HiRAM (C360-C180)

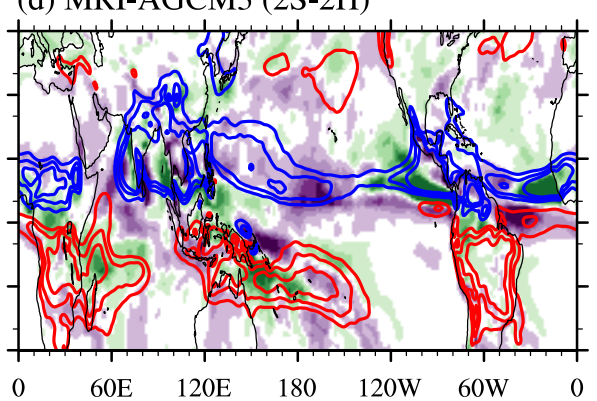

717 Figure 2 As in Figure 1, but for the spatial distribution of the solstitial mode (unit: mm

718 day $^{-1}$ ), defined as the difference between June-September (JJAS) and December-March

719 (DJFM) mean precipitation. The blue and red lines indicate positive and negative values,

720 respectively. 
(a) MetUM N216 Minus TRMM

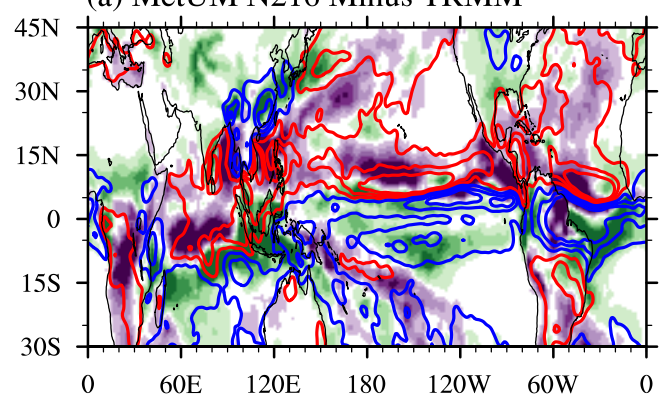

(c) MRI-AGCM3-2H Minus TRMM (b) MetUM (N512-N216)

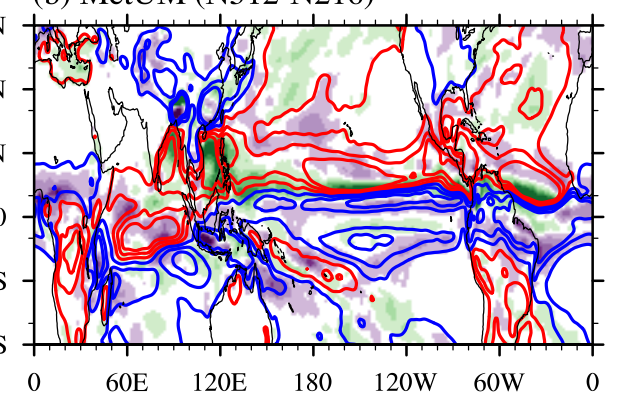

(d) MRI-AGCM3 (2S-2H)
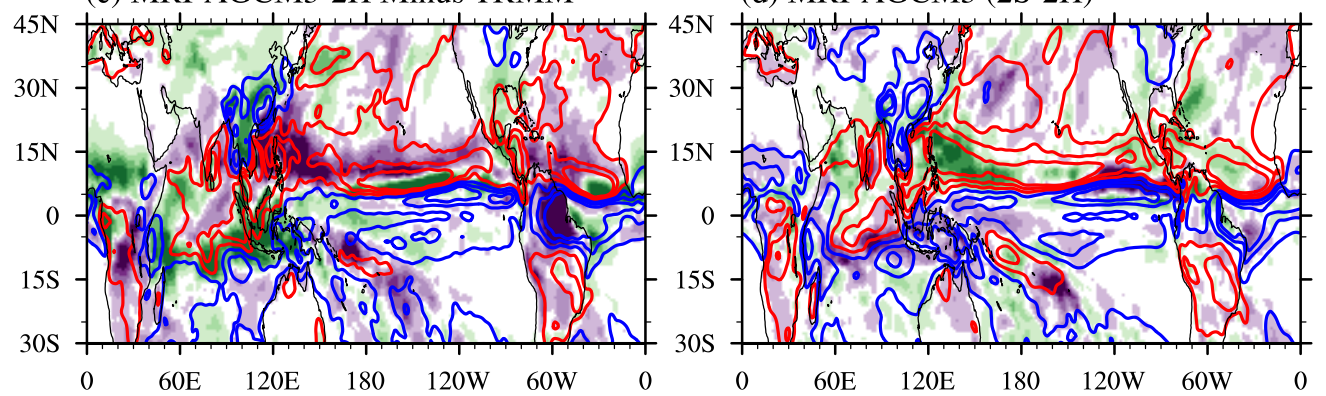

(e) GFDL-HiRAM-C180 Minus TRMM (f) GFDL-HiRAM (C360-C180)

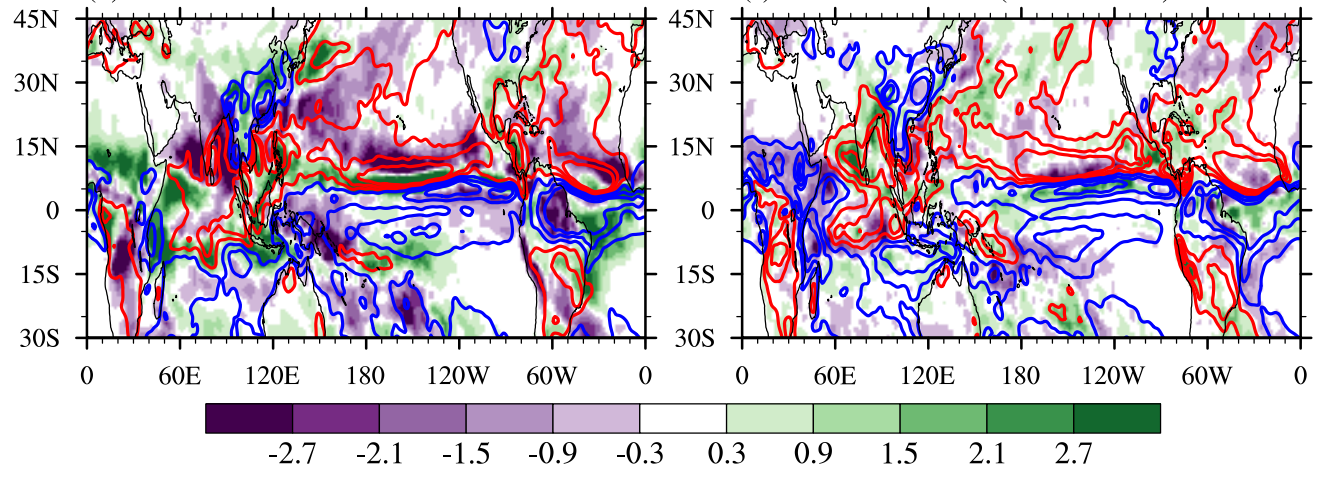

723 Figure 3. As in Figure 1, but for the equinoctial asymmetric mode defined as the differ-

724 ence between April-May (AM) and October-November (ON) mean precipitation. 

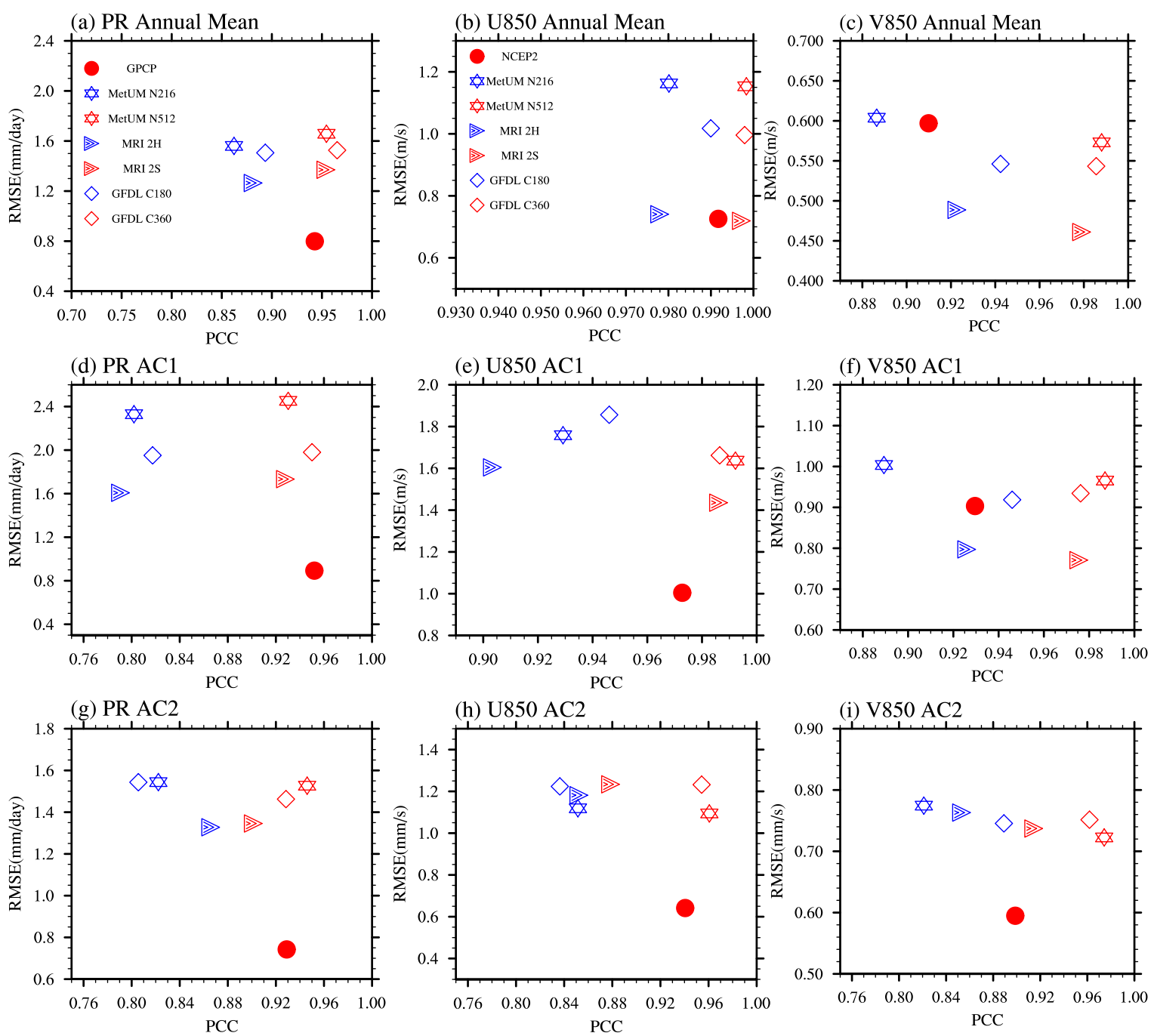

726 Figure 4 Scatter diagrams for the fidelity of simulated precipitation and $850 \mathrm{hPa}$ winds of

727 (a)-(c) annual mean, (d)-(f) solstitial mode, and (g)-(i) equinoctial asymmetric mode 728 against TRMM and CFSR. The abscissa and ordinate are the pattern correlation coeffi729 cients (PCC) and root-mean-square-error (RMSE), respectively. The fidelity of GPCP and

730 NCEP2 against TRMM and CFSR are also shown in dots to represent the observational 731 uncertainty. The stars, triangles and diamonds represent the results from MetUM-GA3,

732 MRI-AGCM3 and GFDL-HiRAM, respectively, with high-resolution configurations in red 733 and low-resolution configurations in blue. 
(a) TRMM

(b) GPCP
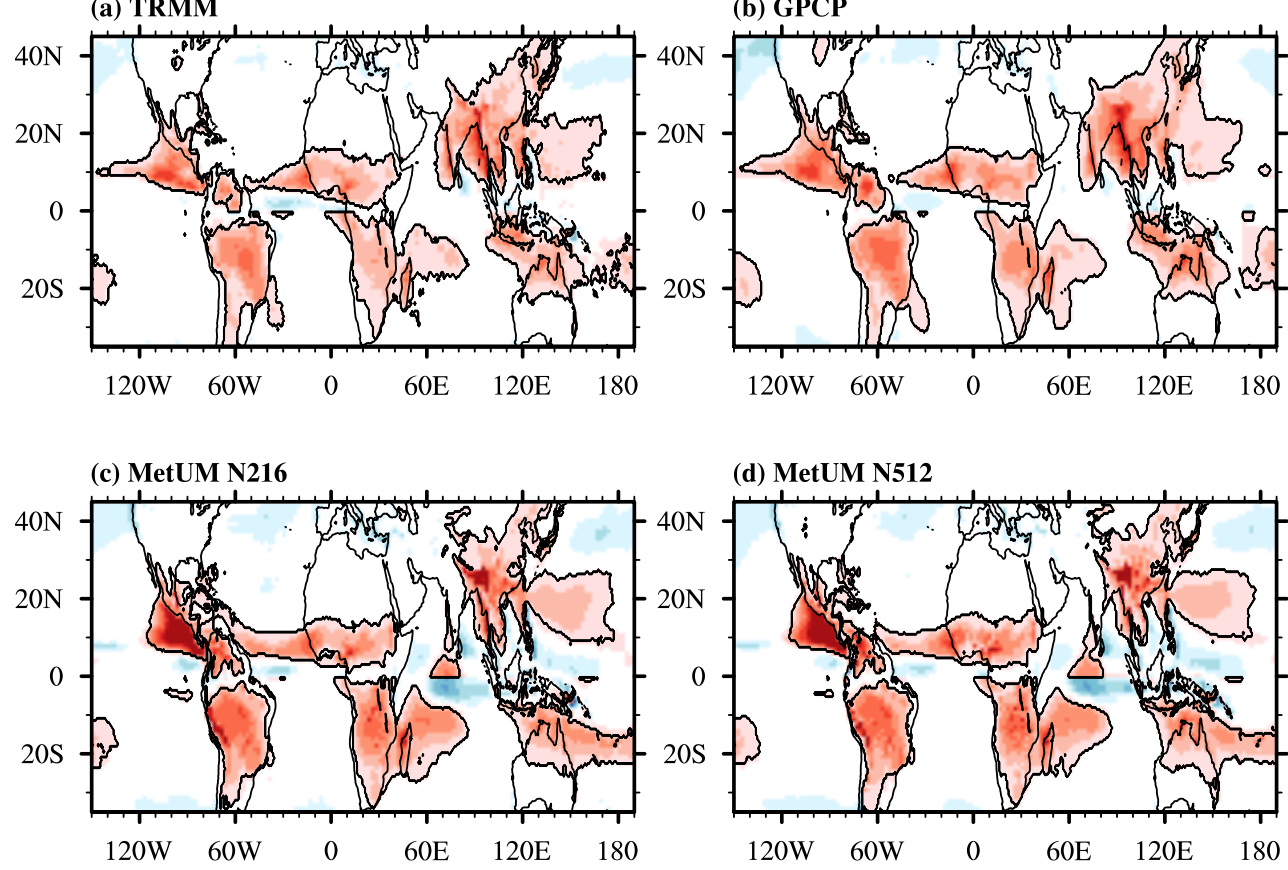

(d) MetUM N512

(e) MRI-AGCM3-2H
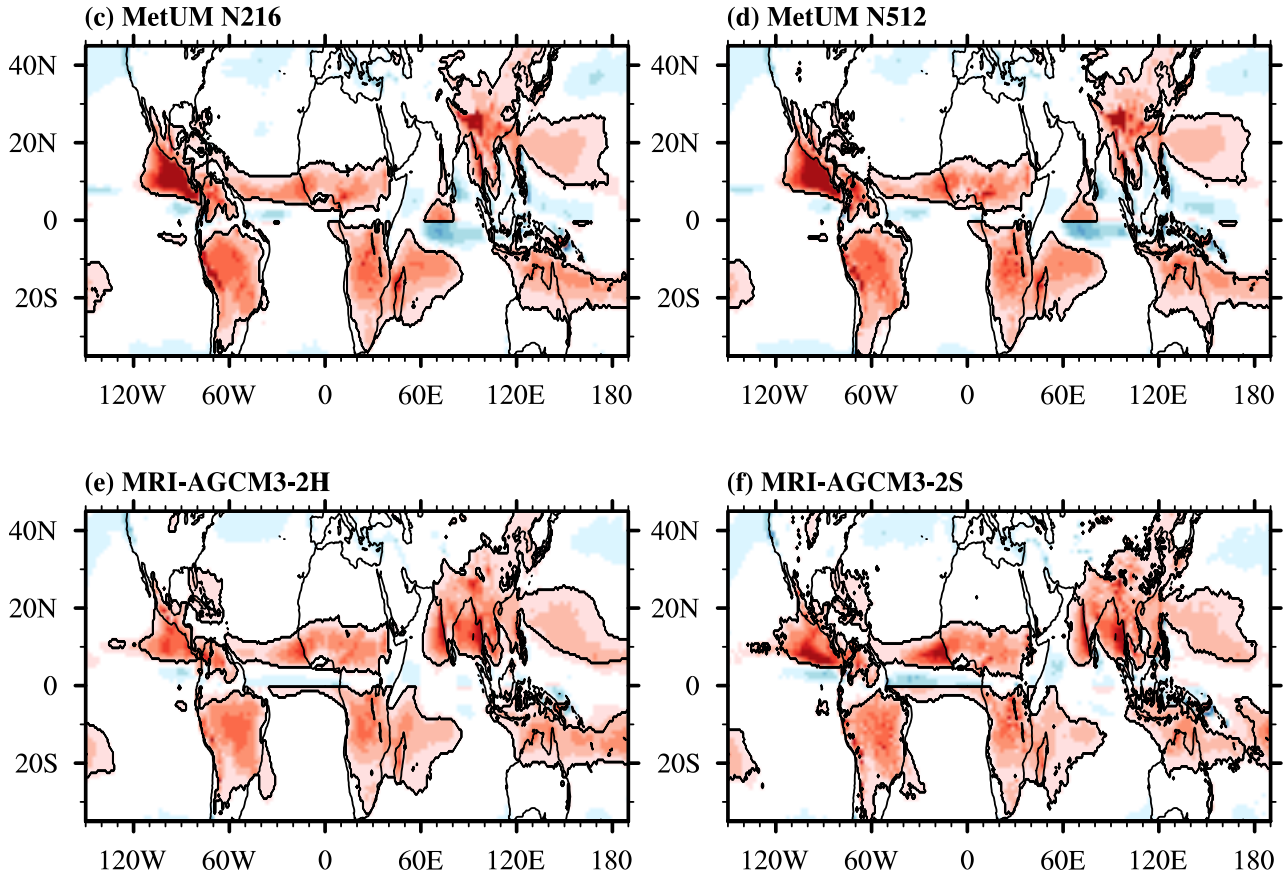

(f) MRI-AGCM3-2S

(g) GFDL-HiRAM-C180

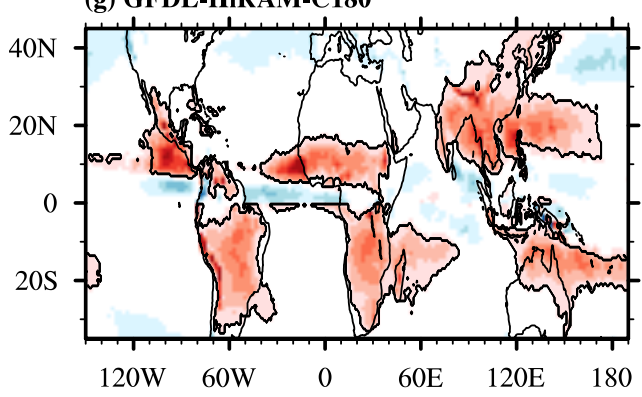

(h) GFDL-HiRAM-C360

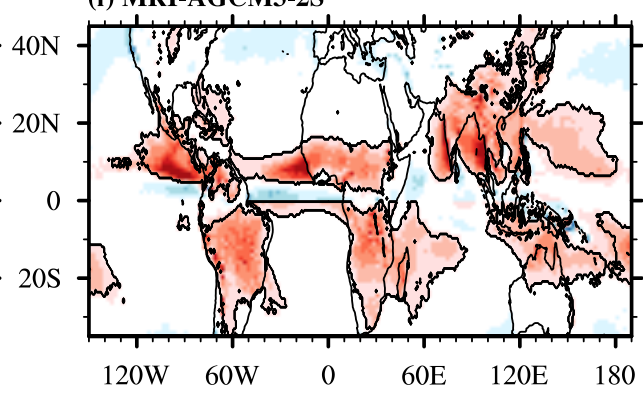

Figure 5 Climatological annual range of precipitation (shaded, units: mm day-1) and globHiRAM-C180, (h) GFDL-HiRAM-C360. The annual range is defined as the May to September (MJJAS) minus November to March (NDJFM) mean precipitation for the Northern 

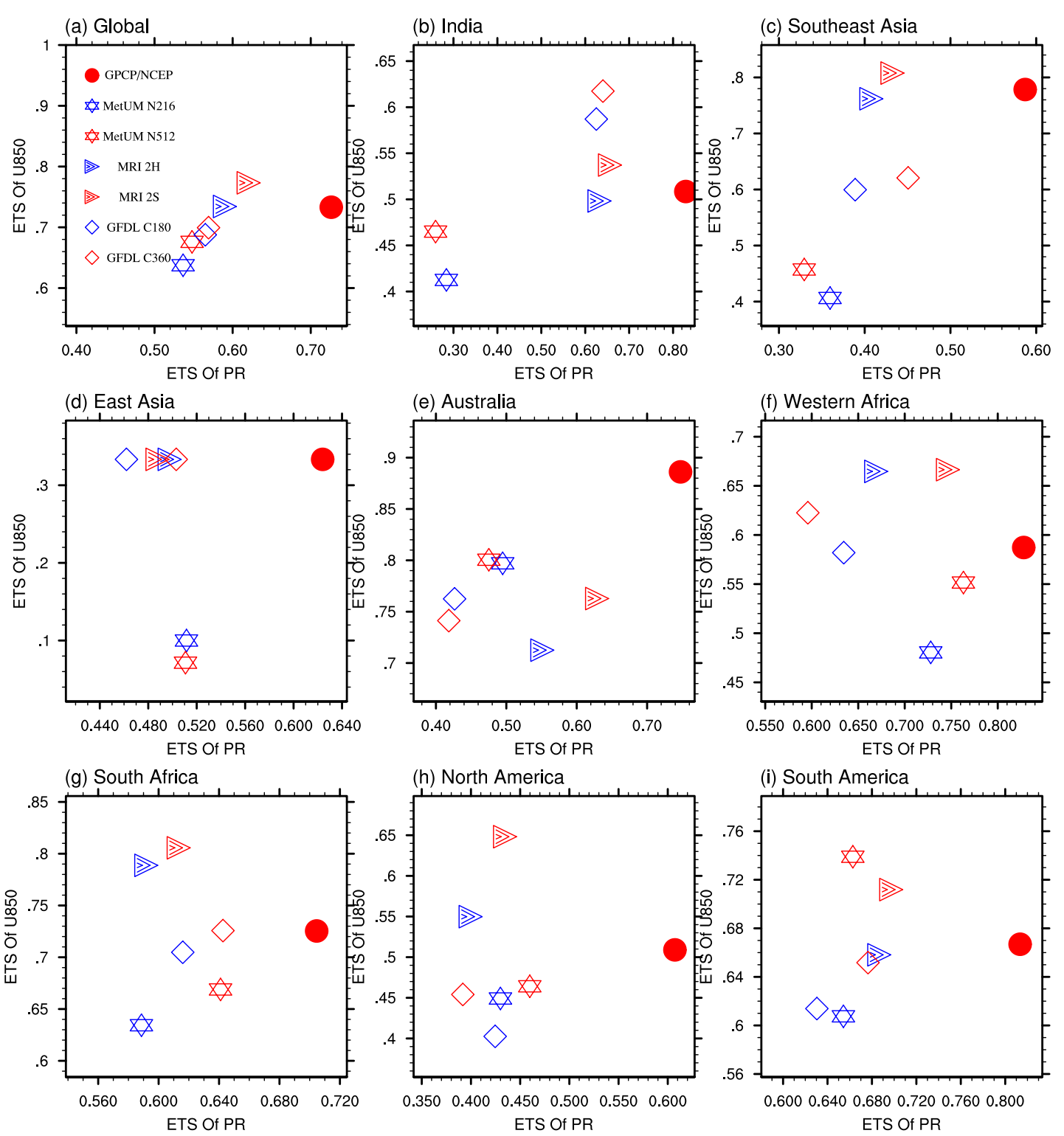

743 Figure 6. The ETS score of monsoon domain simulation over (a) global (GM), (b) Indian

744 (India), (c) Southeast Asian (SAs), (d) East Asian (EAs), (e) Australian (Aus), (f) West Af-

745 rican (WAf), (g) South African (SAf), (h) North American (NAm) and (i) South American

746 (SAm) monsoon. The abscissa (ordinate) is ETS scores of simulated domain derived from

747 precipitation (U850). The fidelity of GPCP against TRMM is shown in dots. The fidelity of

748 GPCP and NCEP2 against TRMM and CFSR are also shown in dots to represent the ob-

749 servational uncertainty. The star, triangle and diamond represent the results from MetUM-

750 GA3, MRI-AGCM3 and GFDL-HiRAM, respectively, with high-resolution configurations 751 in red and low-resolution configurations in blue. 
(a) India
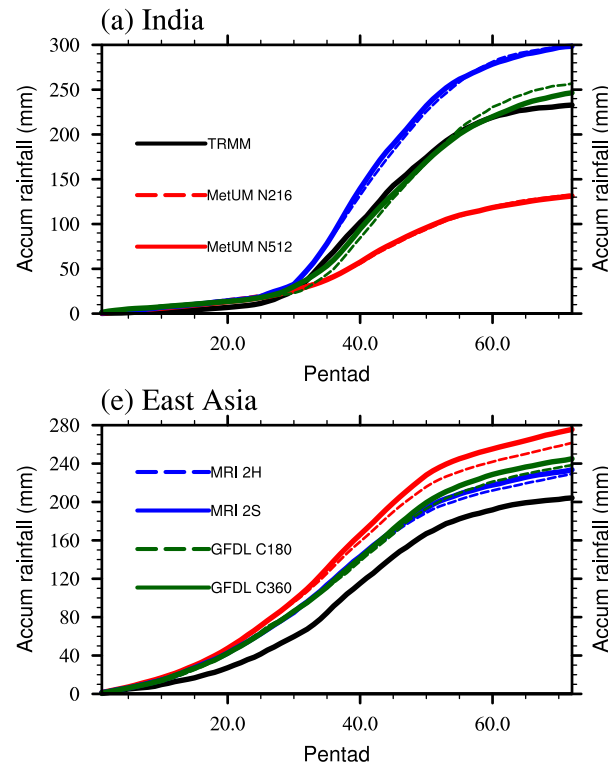

(e) Western Africa

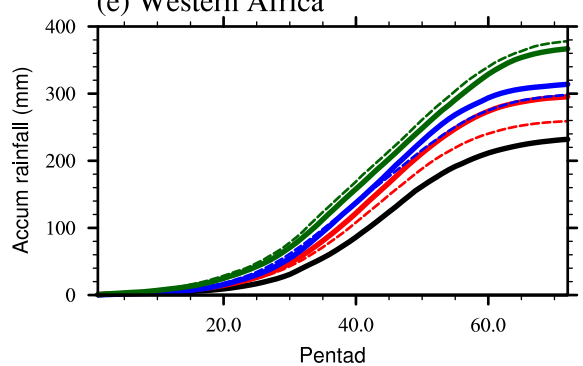

(g) North America

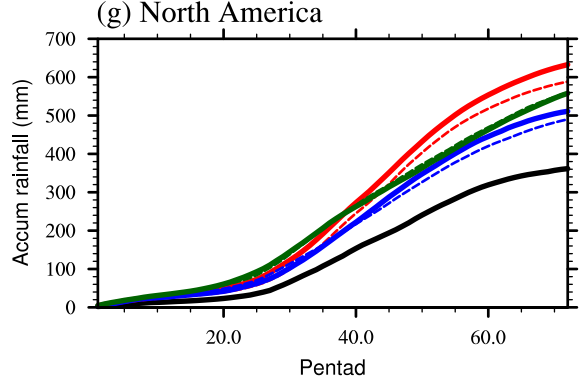

(b) Southeast Asia

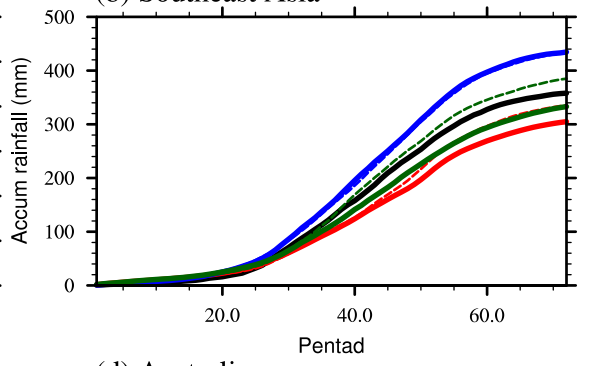

(d) Australia

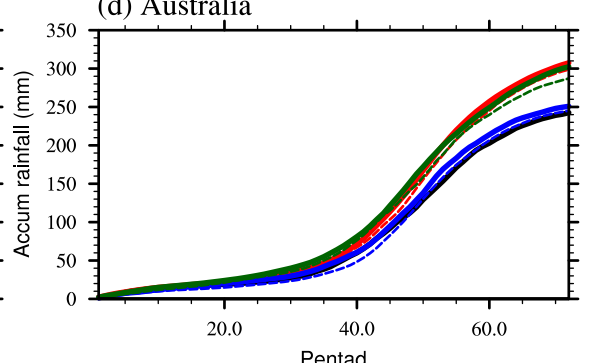

(f) South Africa

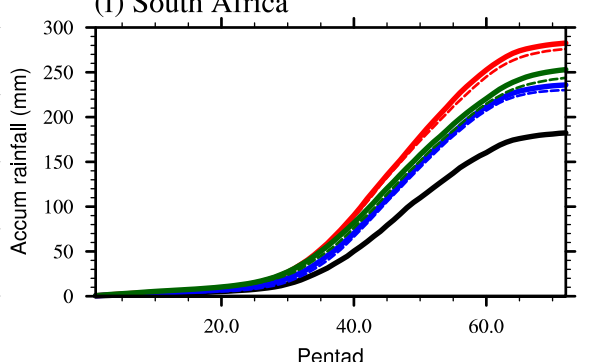

(h) South America

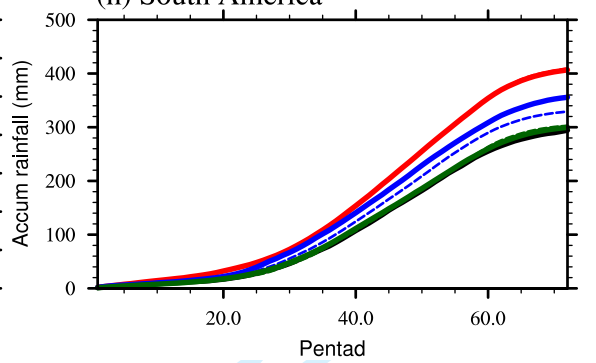

Figure 7 Observed and simulated precipitation accumulations (unit: $\mathrm{mm}$ ) from the first pentad to the end of year, and fractional accumulations (unit: \%) around the monsoon onset pentad averaged over (a) Indian (India), (b) Southeast Asian (SAs), (c) East Asian (EAs), (d) Australian (Aus), (e) West African (WAf), (f) South African (SAf), (g) North American (NAm) and (h) South American (SAm) monsoon. Note: for Southern Hemisphere locations (Australian, South African, and South American monsoons) the pentads were reordered to July-June prior to the analysis. The black, red, blue and green lines represent the results of TRMM, MetUM-GA3, MRI-AGCM3 and GFDL-HiRAM, respectively, with high-resolution configurations in solid lines and low-resolution configuratiosn in dashed lines. 
(a) TRMM

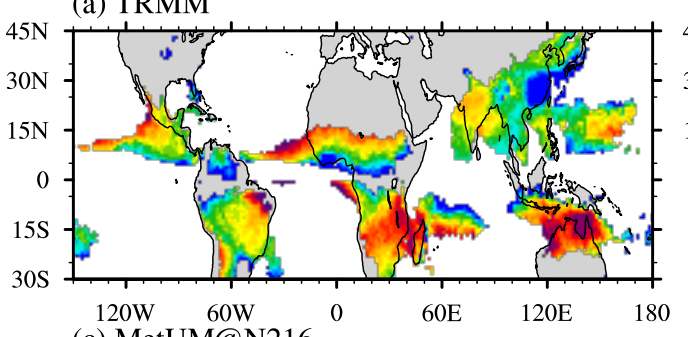

(c) MetUM@N216

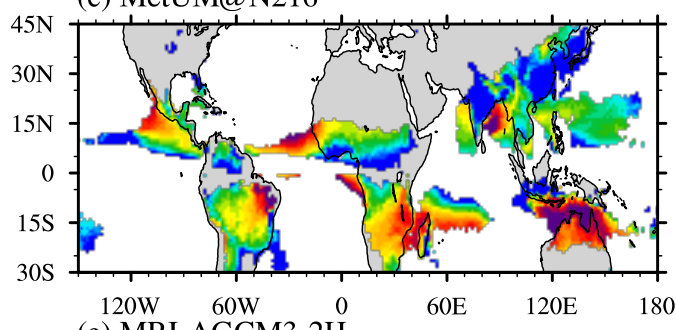

(e) MRI-AGCM3-2H
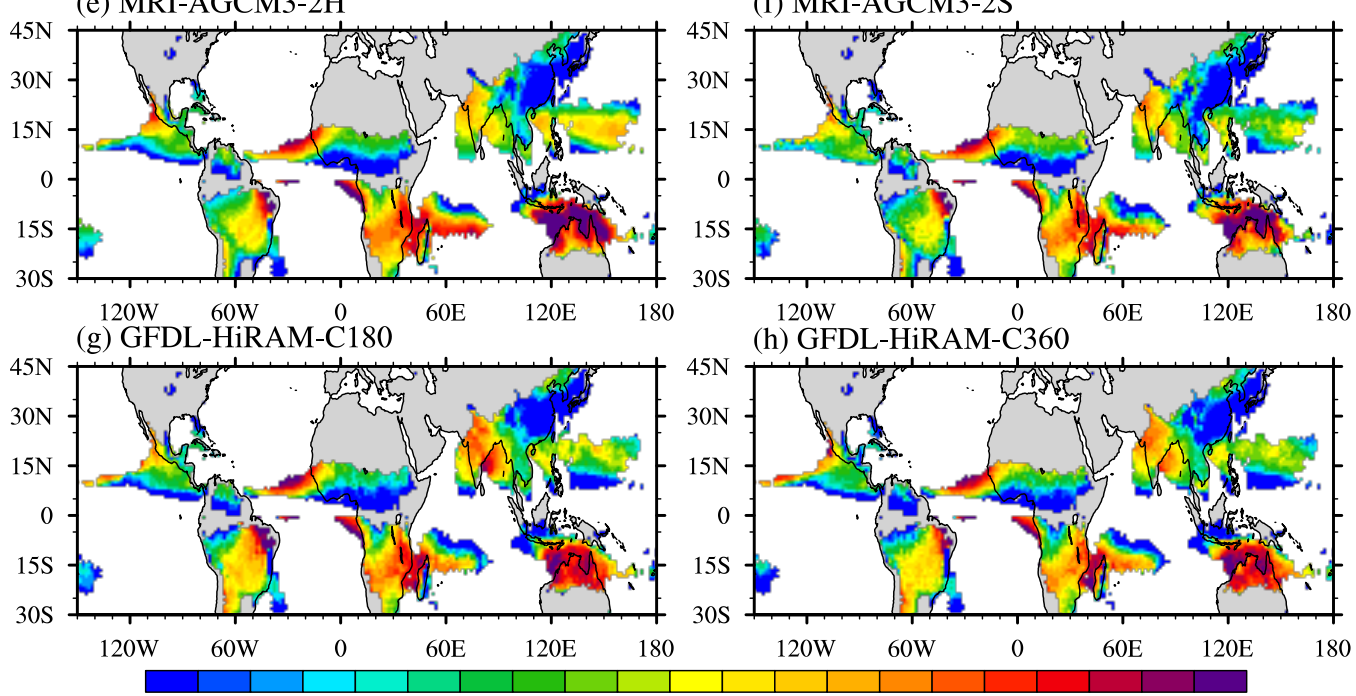

(b) GPCP

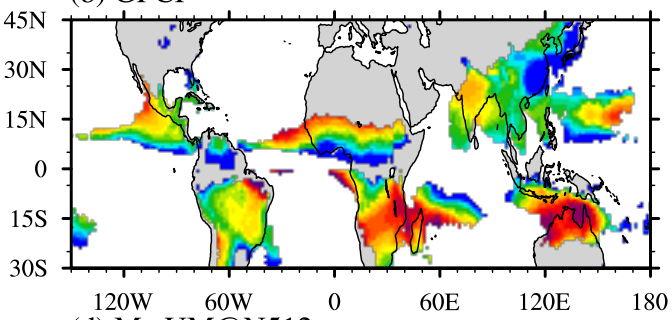

(d) MetUM@N512

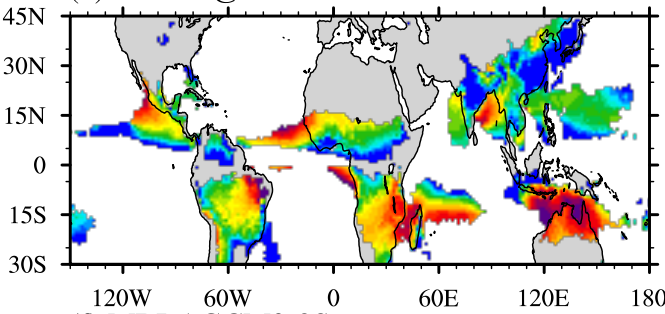

(f) MRI-AGCM3-2S

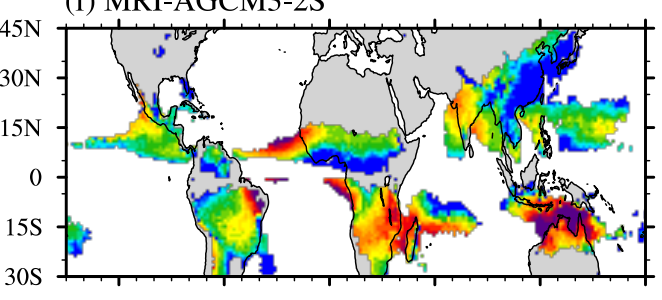

(h) GFDL-HiRAM-C 360

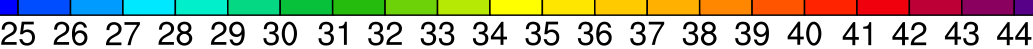

Figure 8 Climatological monsoon onset pentad derived from (a) TRMM, (b) GPCP, (c) MetUM-GA3 N216, (d) MetUM-GA3 N512, (e) MRI-AGCM3-2H, (f) MRI-AGCM3-2S, (g) GFDL-HiRAM-C180, (h) GFDL-HiRAM-C360. The monsoon onset pentad is defined as the pentad when fractional accumulation first becomes $>=0.2$ (Sperber and Annamalai 2014). Note: for Southern Hemisphere locations (Australian, South African, and South American monsoon) the pentads were reordered to July-June prior to the analysis. 
(a) TRMM

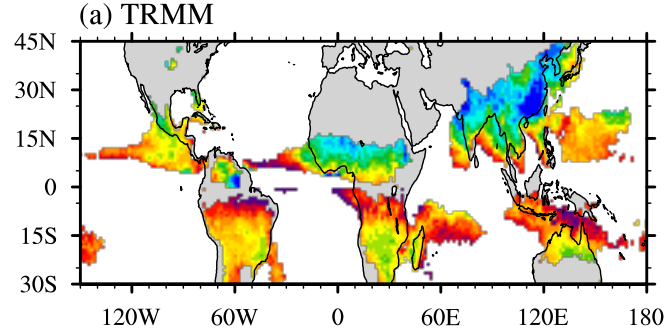

(c) MetUM@N216

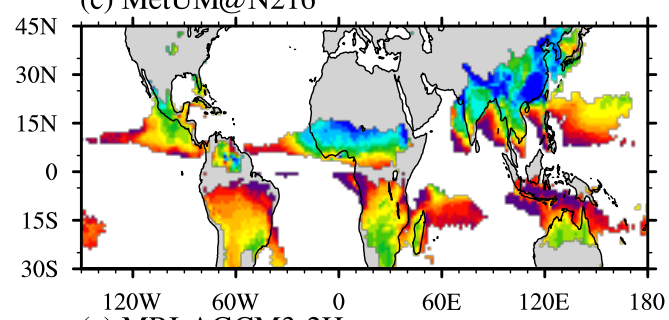

(e) MRI-AGCM3-2H

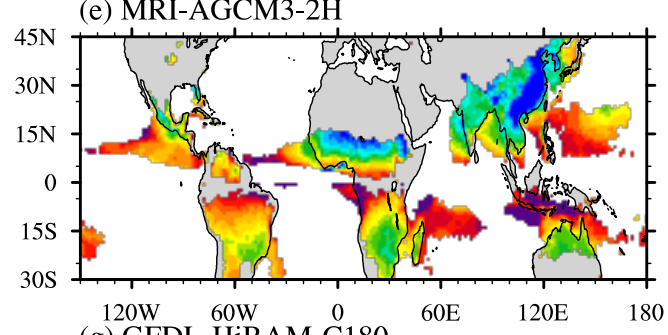

(g) GFDL-HiRAM-C180

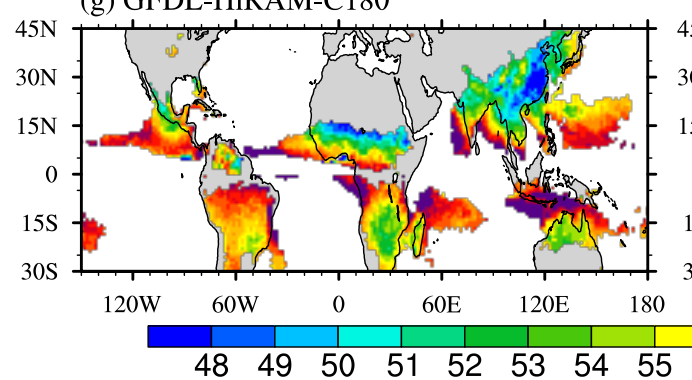

(b) GPCP

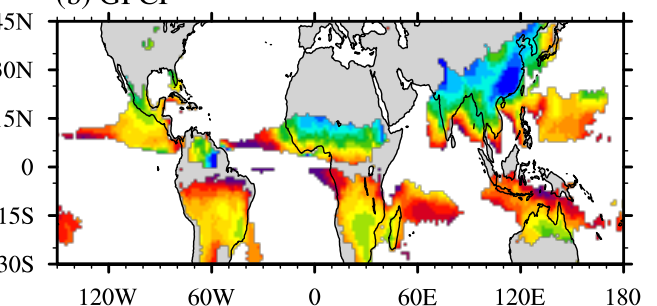

(d) MetUM@N512

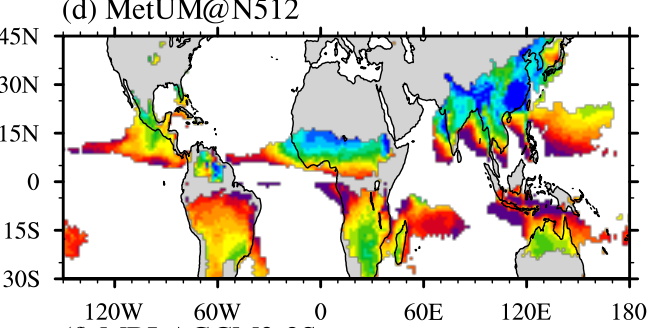

(f) MRI-AGCM3-2S

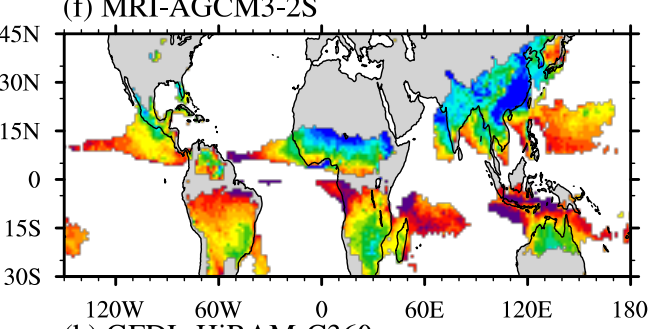

(h) GFDL-HiRAM-C 360

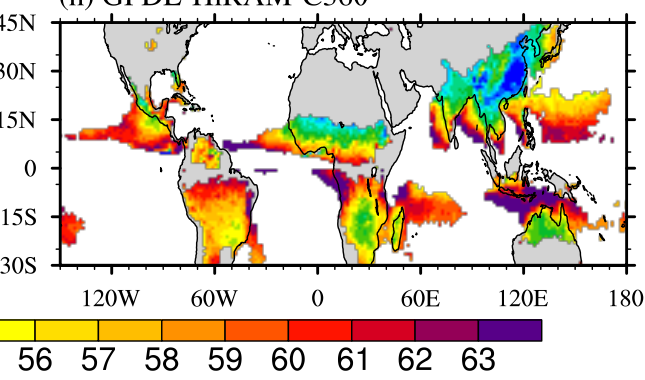

Figure 9 As in Figure 8, but for the monsoon withdrawal pentad, defined as the pentad with fractional accumulation first becomes $>=0.8$ (Sperber and Annamalai 2014). Note: for Southern Hemisphere locations (Australian, South African, and South American monsoon) the pentads were reordered to July-June prior to the analysis. 
(a) India

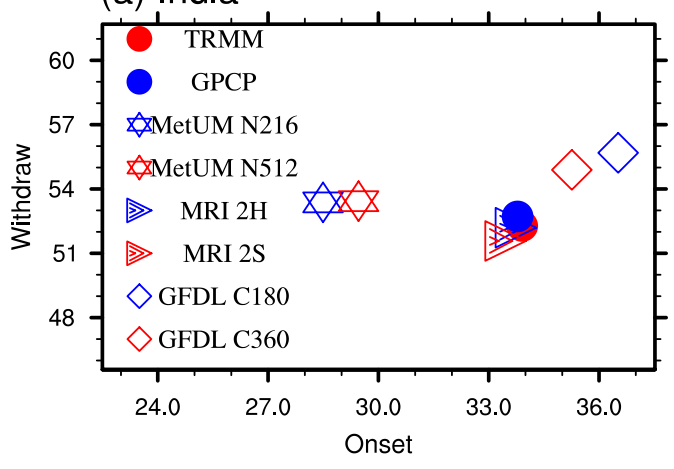

(e) East Asia

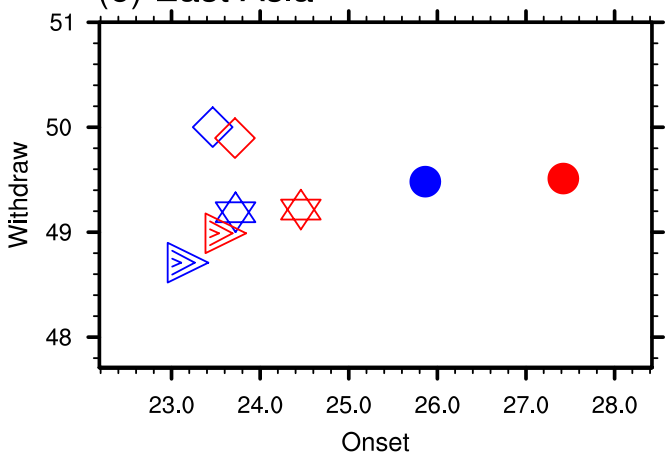

(e) Western Africa

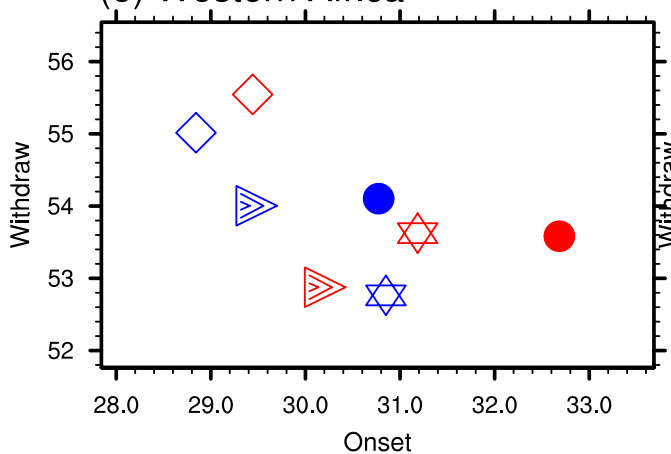

(g) North America

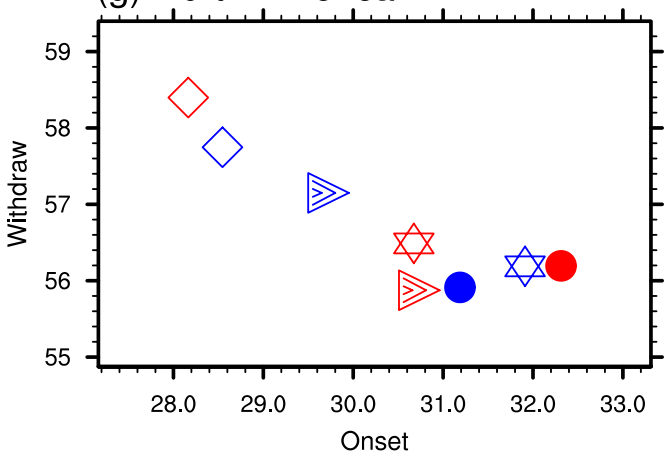

(b) Southeast Asia

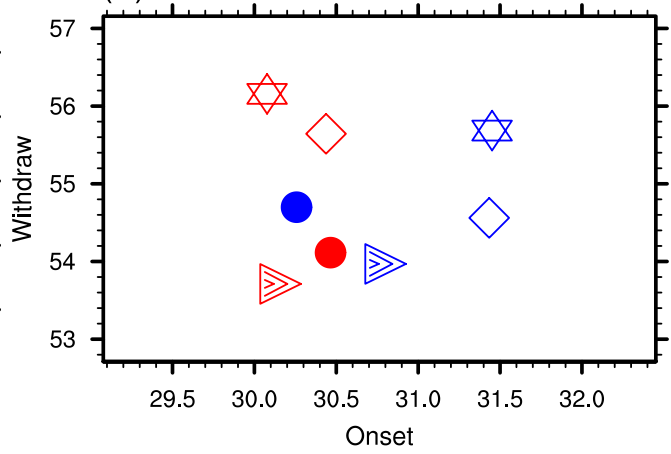

(d) Australia

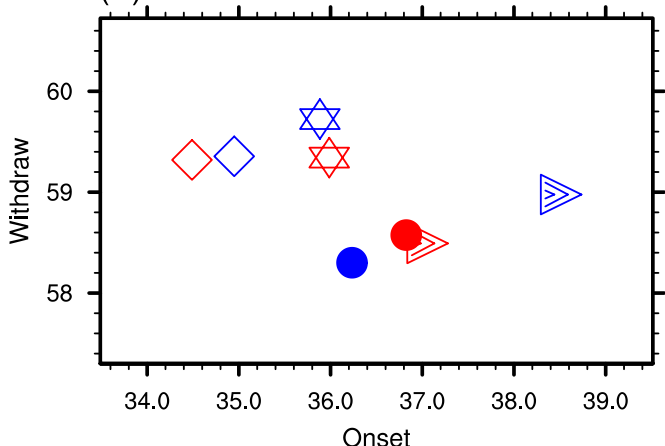

(f) South Africa

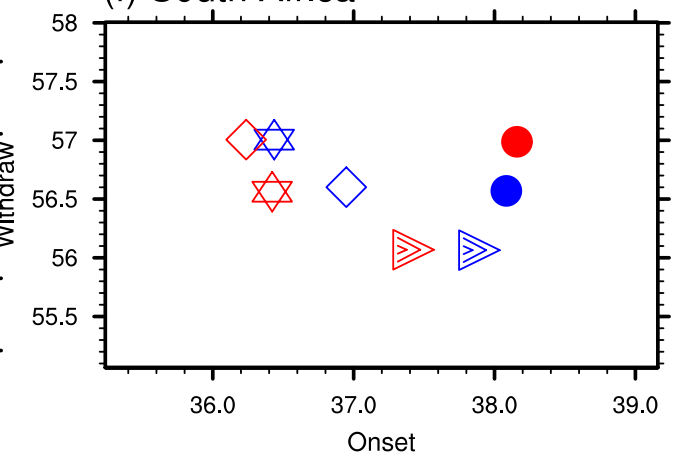

(h) South America

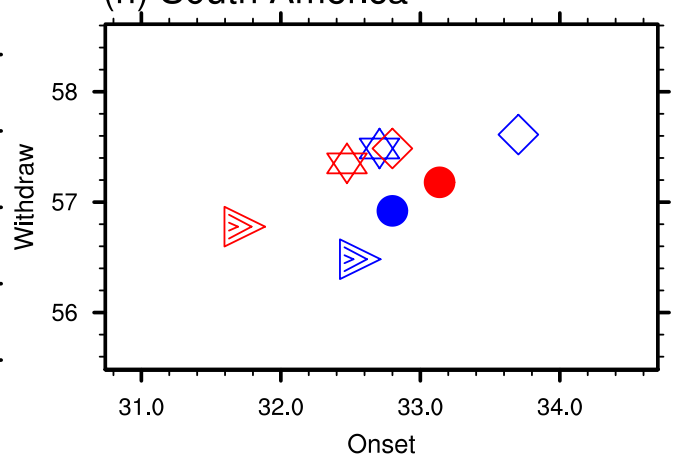

Figure 10. The monsoon onset (x axis) and withdraw pentad (y axis) averaged over (a) Indian (India), (b) Southeast Asian (SAs), (c) East Asian (EAs), (d) Australian (Aus), (e) West African (WAf), (f) South African (SAf), (g) North American (NAm) and (h) South American (SAm) monsoon. Note: for Southern Hemisphere locations (Australian, South 
African, and South American monsoon) the pentads were reordered to July-June prior to the analysis. The dots, stars, triangles and diamonds represent the results from the observations, MetUM-GA3, MRI-AGCM3 and GFDL-HiRAM, respectively, with high-resolution configurations in red and low-resolution configurations in blue. 


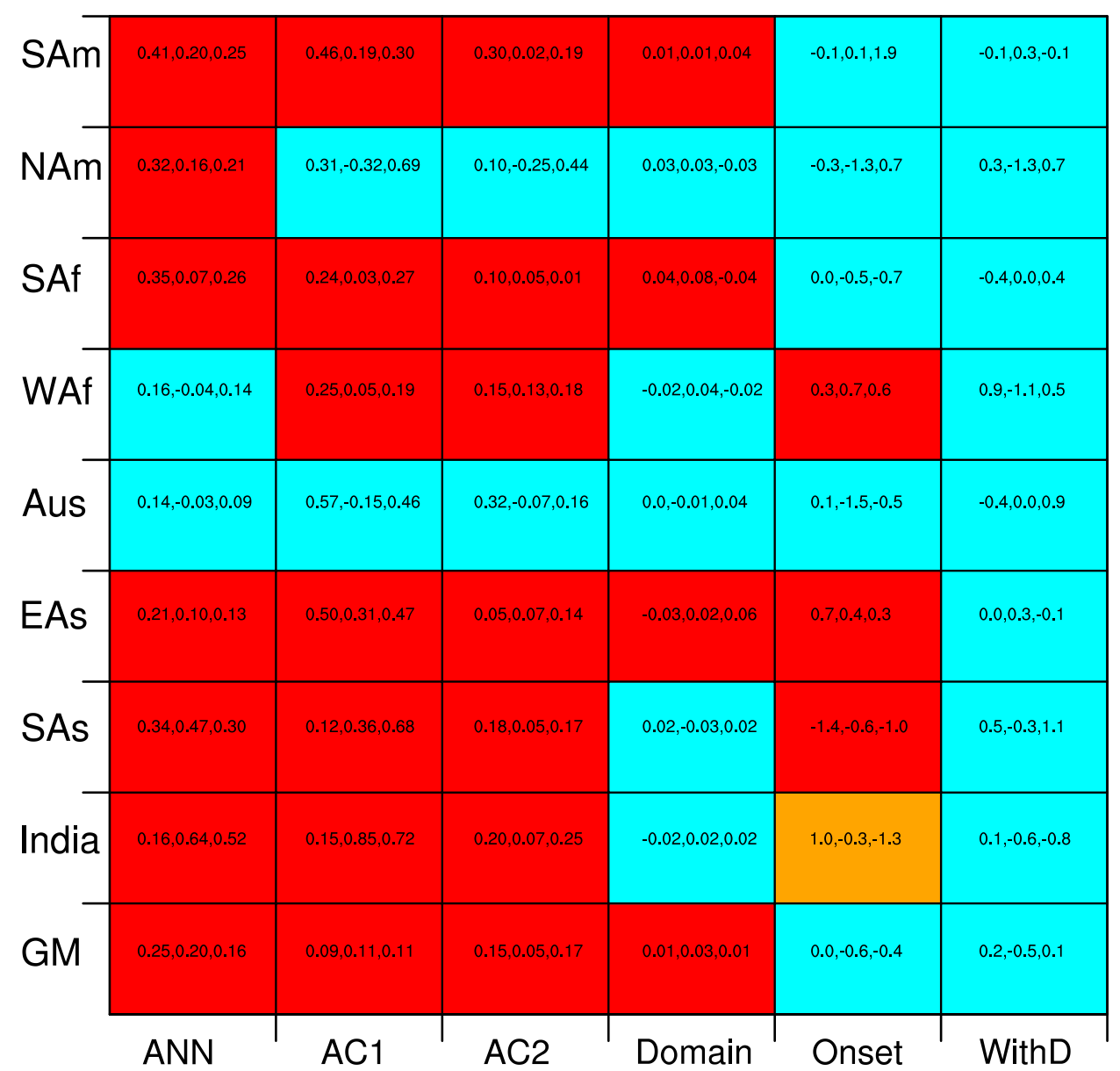

Figure 11 Improvement of the simulation on the annual cycle of global monsoon precipitation with horizontal resolution. Red boxes indicate high-resolution consistently improves performance across all three AGCMs; blue boxes indicate improvements with resolution are inconsistent; orange boxes indicate a better simulation is shown in all three highresolution AGCMs but the responses to resolution are inconsistent across models. The values from left to right in each box are the difference between high- and low-resolution configurations of MetUM-GA3, MRI-AGCM3 and GFDL-HiRAM, respectively. The metric for the annual modes, including annual mean (ANN), solstitial mode (AC1), the equinoctial asymmetric mode (AC2), is the pattern correlation coefficient with TRMM. The metrics for the monsoon domain and monsoon onset/withdrawal are ETS and the onset/withdrawal pentad, respectively. 